\title{
Advances of research on high-speed railway catenary
}

\author{
Zhigang Liu $^{1} \cdot$ Yang Song $^{1} \cdot$ Ye Han ${ }^{1} \cdot$ Hongrui Wang ${ }^{1} \cdot$ Jing Zhang $^{1} \cdot$ \\ Zhiwei Han ${ }^{1}$
}

Received: 14 February 2017/Revised: 24 October 2017/Accepted: 26 October 2017/Published online: 10 November 2017

(C) The Author(s) 2017. This article is an open access publication

\begin{abstract}
The interaction between the catenary and pantograph is one of the most crucial factors that determine the train operation in high-speed railway. The bad state of catenary is able to directly influence the power supply safety of traction power system. In this paper, four aspects on the catenary research of high-speed railway are reviewed in detail, namely the solution methods for catenary equilibrium state, the dynamic modeling methods of catenary, non-contact detection methods of catenary, and the static and dynamic evaluation methods of catenary. In addition, their recent advances are described. For the low solution accuracy of the initial equilibrium state of catenary, the structure finding method with multi-objective constraint and nonlinear finite element procedure are introduced to solve the problem. For the catenary's dynamic modeling, considering the influence of environmental wind on the catenary, environmental wind simulations and wind tunnel tests are used to obtain the
\end{abstract}

Zhigang Liu

liuzg_cd@126.com

Yang Song

Gabrielleyy@163.com

Ye Han

HAN_YE@126.com

Hongrui Wang

soul_wang0@163.com

Jing Zhang

sdzj2006@126.com

Zhiwei Han

illusioncn@163.com

$1 \quad$ School of Electrical Engineering, Southwest Jiaotong University, No. 111, North 1st Section of Second Ring Road, Chengdu 610031, Sichuan, China aerodynamic coefficients and build the wind field along the catenary for analysis of its wind vibration characteristics. In order to improve the detection accuracy of non-contact detection for the catenary, the deep learning theory and real-time detection algorithms should be adopted in the future. In view of the lack of dynamic assessment method for the catenary, the modern spectrum evaluation, timefrequency analysis, big data technology and their combinations will be the important means for future catenary evaluation.

Keywords High-speed railway - Modeling of catenary · Simulation of catenary $\cdot$ Detection of catenary $\cdot$ Evaluation of catenary

\section{Introduction}

The current collection quality of pantograph-catenary directly determines the stable and safe operation of highspeed trains, which is one of the key factors restricting the highest driving speed of trains [1]. Due to the huge cost and difficulties of the field experiment in a real railway line, mathematical modeling has been a prevalent tool to study the dynamic performance of the pantograph-catenary system. Nowadays, the studies of modeling and simulation for railway catenary mainly focused on two points. The first one is the static solution for the initial equilibrium state, which is to calculate the static configuration of the catenary to make it meet the design requirements (such as the tension, arrangement of droppers and pre-sag). The other one is the dynamic solution for the pantograph-catenary interaction, including the dynamic modeling method, solution algorithm as well as some simulations for external 
disturbances, such as wind, iced line and irregularities of contact wire.

In 2012, the Ministry of Railways of China proposed 'High-speed Railway Power Supply Security Detection and Monitoring System,' namely ' $6 \mathrm{C}$ ' system. The core idea is to use the captured pictures and video to realize the noncontact detection. However, the level of automatic image recognition needs to be improved. High-speed railway pantograph-catenary system is a random vibration system, and its dynamic characteristic evaluation is difficult. At present, the dynamic characteristic evaluation of pantograph-catenary system is mainly based on statistical parameters, such as the stationary mean value and variance in the European standard [2]. These evaluation indexes assume that the data of pantograph-catenary system is generalized stationary, which cannot satisfy the requirement for dynamic analysis of high-speed pantographcatenary system; besides, it is difficult to evaluate the pantograph-catenary system performance efficiently using a single statistic.

The overview in this paper mainly focuses on four aspects of the current research, which are the simulation, modeling, detection and evaluation of catenary. Firstly, the existing solution methods for the initial equilibrium state are summarized. The common solution methods for linear and nonlinear dynamics of catenary are classified and discussed. And, previous studies on the effect of environmental wind on catenary are reviewed. Then, non-contact detection techniques for catenary, especially various detection methods and strategies, are summarized. The state evaluation of catenary is reviewed, which mainly focuses on evaluation methods on the static and dynamic state of catenary and their validity. At last, addressing the current shortfalls, some suggestions are proposed for future research.

\section{Solution for catenary equilibrium state}

A high-speed railway catenary is mainly composed of a messenger wire, droppers and a contact wire [3]. The messenger and droppers are used to hang the contact wire to keep it level or having a specific pre-sag, as shown in Fig. 1. Because of the significant effect of the initial static configuration on the dynamic performance, the exact calculation of the initial configuration is the premise of studying the dynamic response of catenary. The solution for catenary equilibrium state is to calculate the initial configuration according to the specific design requirements (such as the arrangement of droppers, structural height, tension, length of span, reserved sag). In earlier calculation methods, the initial configuration of the contact wire is always neglected, which assumes that the contact wire is

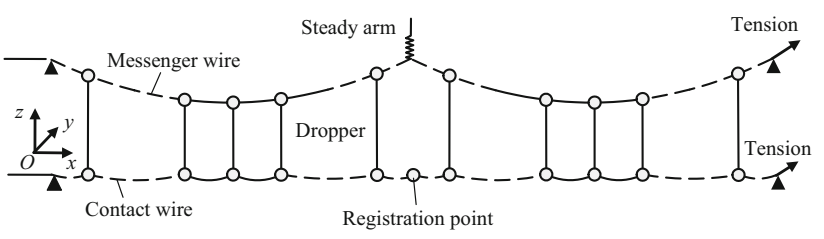

Fig. 1 Sketch of catenary system

absolutely level and neglects the gravity [4]. With the development of high-speed railway, some higher requirements are proposed for the exact solution of the initial configuration. Many new methods have been proposed to calculate the initial configuration of catenary.

In general, the most fast shape-finding method is the parabolic method, which assumes the initial configuration of messenger wire as a quadratic parabola [5] to determine the length of each dropper. This method is prevalently used in industry because of its simple theory and fast calculation speed. But a significant shortcoming of this method is that it neglects the sag of contact wire and cannot reflect the mechanical equilibrium relationship. Addressing this shortcoming, Ref. [6] propose the separate model method to calculate the pre-sag of the messenger wire and the lengths of droppers. This method separates the catenary into two sub-systems, namely the messenger wire system and the contact wire-dropper system. The contact wire and messenger wire are modeled with Euler-Bernoulli beam. By fixing the dropper points on the messenger wire, the dropper forces are calculated to keep the contact wire level as shown in Fig. 2a. Then the dropper forces are exerted on the messenger wire to calculate the sag of the messenger wire and the lengths of droppers (Fig. 2b). In Ref. [7], the geometrical nonlinearity of the messenger wire is considered and its bending moment is neglected. A nonlinear cable element is adopted to model the messenger wire. In this method, the pre-sag of contact wire cannot be described. In order to overcome this disadvantage, Ref. [8] introduces the large deformation beam element and iteration solution into the traditional separate model method. The proposed method could solve the static configuration of catenary more effectively. Reference [9] studies the effect of geometrical nonlinearity on static configuration of the catenary and indicates that the geometrical nonlinearity of the contact/messenger wire can be neglected in the solution of the static configuration.

Even if the separate model method shows good efficiency in solving the initial configuration of the catenary, the catenary should be separated into two sub-systems, which is not convenient for further dynamic solution. Hence, Ref. [10] proposes a negative-sag method to calculate the initial configuration. In this method, the catenary 


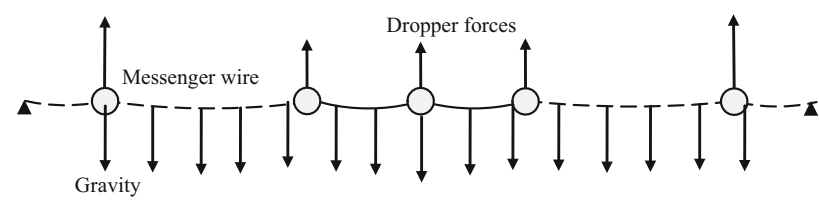

(a)

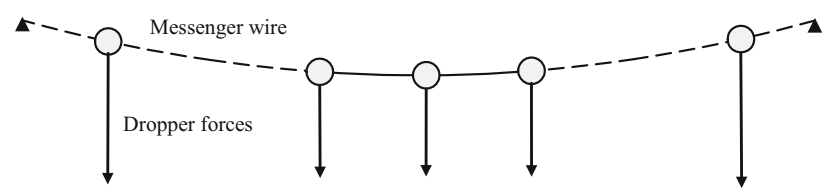

(b)

Fig. 2 Separate model method: a contact wire-dropper sub-system; b messenger wire sub-system

is not separated into several sub-systems. Instead, a specific negative sag is given for a catenary as shown in Fig. 3. Then the gravity is exerted on the catenary to calculate the real sag in this circumstance, and the calculation result is compared with the design requirement to update the negative-sag set for the next iteration calculation. Thus the initial configuration can be calculated to guarantee that the contact wire is level or has a specific pre-sag.

Apart from the negative-sag method, Lopez-Garcia et al. [11] establish a whole catenary model based on the explicit expressions of cable element and adopt an iteration algorithm to solve the initial configuration of catenary. Compared with the traditional finite element method, this method has better efficiency and accuracy. Lee and Jung $[12,13]$ derive the equation for calculating the length of droppers and pre-sag of messenger wire. This method assumes that the contact wire's sag in the $i$ th dropper point can be calculated as

$d_{i}=\frac{w_{\mathrm{c}}}{2 T_{\mathrm{w}}}\left(x_{i}-x_{1}\right)\left(L_{p}-x_{i}+x_{1}\right)$,

where $w_{\mathrm{c}}$ is the self-weight of contact wire per unit length, $T_{\mathrm{w}}$ is the tension acting on contact wire, $x_{i}$ is the dropper point, $x_{1}$ is the interval between the first dropper and the registration point, and $L_{\mathrm{p}}$ is the length of span. According to the equilibrium of the dropper forces acting on messenger and contact wires, the sag of messenger wire in each dropper point can be derived:

$c_{i}=\frac{1}{T_{\mathrm{m}}}\left(R_{\mathrm{A}} x_{i}-\frac{w_{\mathrm{m}} x_{i}^{2}}{2}-\sum_{k=1}^{i-1} F_{k}\left(x_{i}-x_{k}\right)\right)$,

where $T_{\mathrm{m}}$ is the messenger wire tension, $R_{\mathrm{A}}$ is the support reaction force, $w_{\mathrm{m}}$ is the self-weight of messenger wire per unit, and $F_{k}$ is the dropper force acting on the $k$ th dropper.

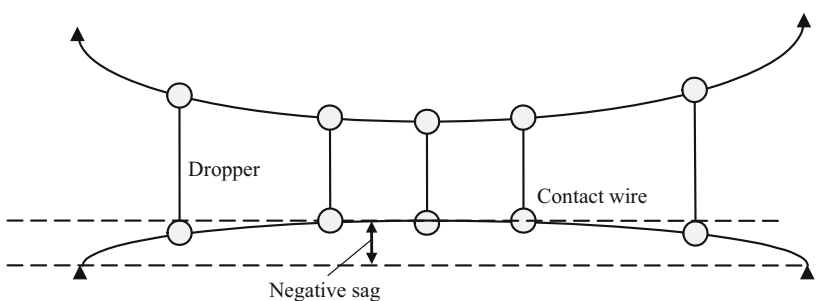

Fig. 3 Negative-sag method

This method is very convenient to implement without very complex finite element solution procedures.

It should be noted that the above solution methods are all based on the assumption that the initial lengths of messenger and contact wires are certain. In fact, when the tension, pre-sag of contact wire, length of span, arrangement of droppers are given, the initial length of messenger and contact wires are uncertain. Tur et al. [14] proposed a catenary shape-finding method for catenary based on the absolute nodal coordinate method. This method transfers the shape-finding problem of catenary to an optimization problem to ensure a minimum solution of the following function:

$\min \frac{1}{2} \sum_{\forall p}\left(q_{z}(p)-h_{\mathrm{c}}\right)^{2}$,

where $q_{z}(p)$ is the initial displacement in $z$ direction on the $p$ th point of contact wire, and $h_{\mathrm{c}}$ is the height of contact wire given by the design requirement. The constraint conditions are defined as

$\boldsymbol{f}\left(\boldsymbol{q}, k_{1} l_{0}\right)=\mathbf{0}$,

$\boldsymbol{c}_{\mathrm{I}}\left(\boldsymbol{q}, k_{1} l_{0}\right)=\mathbf{0}$,

$\boldsymbol{c}_{\mathrm{II}}(\boldsymbol{q})=\mathbf{0}$,

where $\boldsymbol{q}$ is the vector of global coordinate of all elements. $l_{0}$ is the initial length of such an element; $k_{1}$ is the modification coefficient of the initial length; $f, c_{\mathrm{I}}$ and $\boldsymbol{c}_{\mathrm{II}}$ are the function symbols. Equation (4a) represents the mechanical equilibrium condition of each node, Eq. (4b) denotes the external forces acting on the catenary, and Eq. (4c) represents the geometrical relationship of each node. Through the Newton-Raphson iteration, the initial configuration of catenary can be solved considering straight line, curve and some other actual conditions. The good convergence and efficiency can be verified.

Similarly, in order to consider the change of the initial length of messenger and contact wires, Refs. [15, 16] propose a nonlinear model based on flexible cable and truss elements. The TCUD (target configuration under dead loads) method is introduced to find the initial shape of 
catenary. The differentiation for each cable or truss element is conducted to generate the stiffness matrix related to the incremental and initial length of each element. By assembling the global stiffness matrix $\boldsymbol{K}_{\mathrm{C}}$ and $\boldsymbol{K}_{\mathrm{G}}$ (the former is related to incremental coordinate, and the latter is related to the initial length of each element), the following equation of motion can be obtained:

$\mathrm{d} \boldsymbol{F}_{\mathrm{C}}=\boldsymbol{K}_{\mathrm{C}} \mathrm{d} \boldsymbol{X}+\boldsymbol{K}_{\mathrm{G}} \mathrm{d} \boldsymbol{L}_{0}$,

where $\mathrm{d} \boldsymbol{X}$ and $\mathrm{d} \boldsymbol{L}_{0}$ are the vectors for incremental coordinate and incremental initial length, respectively; and $\mathrm{d} \boldsymbol{F}_{\mathrm{C}}$ is the unbalanced force vector. According to the design requirement, the constraint conditions are exerted on Eq. (5) to reduce the number of unknowns and keep the number of unknowns equal to the number of equations. At last the Newton-Raphson iteration is utilized to calculate the initial equilibrium state of catenary. Figure 4 presents the comparison of calculating results between the TCUD and Lee's method. The parameters are adopted according to [13]. It can be seen that the results of the two methods show excellent agreement with each other. Only a small difference from the design standard $(0.025 \mathrm{~m})$ can be
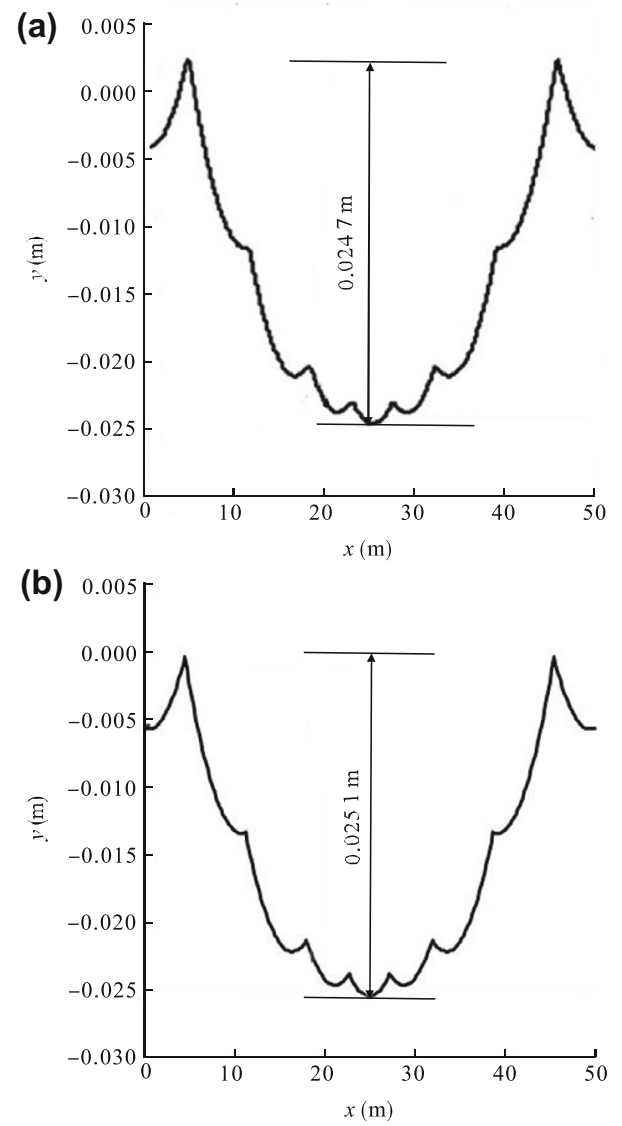

Fig. 4 Contact wire sag: a Lee method; b TCUD observed. Table 1 shows the comparison of solution methods for the initial configuration of catenary in detail.

\section{Dynamic simulation of catenary}

The main object of catenary dynamic simulation is to construct the dynamic model of the catenary and solve the dynamic behavior of catenary traversed by a pantograph, which can provide a platform for the further analysis of the pantograph-catenary interaction. Recently, the modeling method for the catenary has been developed from the simple linear model to the nonlinear model by considering the large deformation of the contact/messenger wire and different working conditions of droppers. In order to improve the accuracy, various kinds of external perturbations are considered.

\subsection{Dynamic modeling of catenary}

The main modeling methods for the catenary can be divided into three types: finite difference model, finite element model and modal superposition method.

\subsubsection{Finite difference model}

Based on the finite difference method, Poetsch and Finner $[17,18]$ propose a 2D catenary model based on EulerBernoulli beam, whose governing equation is

$\rho A \frac{\partial^{2} w}{\partial t^{2}}=T \frac{\partial^{2} w}{\partial x^{2}}-E I \frac{\partial^{4} w}{\partial x^{4}}-\beta \frac{\partial w}{\partial t}+q(x, t)$,

where $\rho$ and $A$ is the density and cross-sectional area of catenary, respectively (so $\rho A$ is the self-weight of cable per unit length); $E$ and $I$ is the Young's modulus and inertia moment of catenary, respectively (so $E I$ is the bending stiffness); $T$ is the tension; $\beta$ is the damping coefficient; $w$ is the displacement in vertical direction; and $q(x, t)$ is the external forces exerted by pantograph. According to the finite difference method, the explicit two-step iteration algorithm is utilized to solve Eq. (6):

$y^{(n+1)}=2 y^{n}-y^{(n-1)}+\Delta t^{2} f\left(y^{(n)}\right)$,

where $n+1, n$ and $n-1$ are time steps; $y$ is the vertical displacement of contact wire; the function $f\left(y^{(n)}\right)$ denotes the acceleration of contact wire and is defined as follows:

$\frac{\mathrm{d}^{2} y}{\mathrm{~d} t^{2}}-\omega^{2} y=f(y)$

where $\omega$ is the natural frequency of the contact wire. This method is more convenient to implement compared with 
Table 1 Comparison of initial configuration solutions of catenary

\begin{tabular}{|c|c|c|c|c|c|}
\hline Solution method & $\begin{array}{l}\text { Separate } \\
\text { system }\end{array}$ & $\begin{array}{l}\text { Nonlinearity of } \\
\text { wire }\end{array}$ & Types of cable/beam & $\begin{array}{l}\text { Contact wire } \\
\text { sag }\end{array}$ & $\begin{array}{l}\text { Initial length of } \\
\text { cable }\end{array}$ \\
\hline Parabola & $\mathrm{Y}$ & $\mathrm{N}$ & $\mathrm{N}$ & $\mathrm{N}$ & $\mathrm{N}$ \\
\hline Traditional separate model & $\mathrm{Y}$ & $\mathrm{N}$ & Euler-Bernoulli beam & $\mathrm{N}$ & $\mathrm{N}$ \\
\hline Developed separate model & $\mathrm{Y}$ & $\mathrm{Y}$ & Nonlinear cable or beam & $\mathrm{N}$ & $\mathrm{N}$ \\
\hline $\begin{array}{l}\text { Developed iteration separate } \\
\text { model }\end{array}$ & $\mathrm{Y}$ & $\mathrm{Y}$ & Nonlinear beam & $\mathrm{Y}$ & $\mathrm{N}$ \\
\hline Negative sag & $\mathrm{N}$ & $\mathrm{Y}$ & Nonlinear cable or beam & $\mathrm{Y}$ & $\mathrm{N}$ \\
\hline Force equilibrium & $\mathrm{N}$ & Y & $\begin{array}{l}\text { Absolute nodal coordinate formulation } \\
\text { (ANCF) beam }\end{array}$ & $\mathrm{Y}$ & $\mathrm{N}$ \\
\hline Explicit cable formulas & $\mathrm{N}$ & $\mathrm{Y}$ & Nonlinear cable & Y & $\mathrm{N}$ \\
\hline Objective function & $\mathrm{N}$ & Y & ANCF beam & Y & $\mathrm{Y}$ \\
\hline TCUD & $\mathrm{N}$ & $\mathrm{Y}$ & Flexible cable & $\mathrm{Y}$ & $\mathrm{Y}$ \\
\hline
\end{tabular}

the traditional finite element method (FEM), and the solution speed is quite fast.

\subsubsection{Finite element model}

Finite element method is the most prevalent method to model the catenary. Mostly, Euler-Bernoulli beam is used to model the contact and messenger wires. According to the geometrical structure of catenary, the global stiffness matrix $\boldsymbol{K}_{\mathrm{g}}=\sum_{\text {FEM }} \boldsymbol{K}_{\mathrm{e}}$, which is generated by FEM, where $\boldsymbol{K}_{\mathrm{e}}$ is the element stiffness matrix. A three-dimensional beam element stiffness matrix can be calculated as the summation of $\boldsymbol{K}_{\mathrm{e}}^{(1)}$ and $\boldsymbol{K}_{\mathrm{e}}^{(2)}: \boldsymbol{K}_{\mathrm{e}}^{(1)}$ is the linear stiffness matrix as shown in Eq. (9), and $\boldsymbol{K}_{\mathrm{e}}^{(2)}$ is the initial stress stiffness matrix as shown in Eq. (10), which is used to model the deformation of beam element.

$\boldsymbol{K}_{\mathrm{e}}^{(1)}=\left[\begin{array}{cccccccccc}\frac{E A}{l} & & & & & & & & \\ 0 & \frac{12 E I}{l^{3}} & & & & & & & \\ 0 & 0 & \frac{12 E I}{l^{3}} & & & \multicolumn{5}{c}{\text { Symmetric }} \\ 0 & 0 & -\frac{6 E I}{l^{2}} & \frac{4 E I}{l^{3}} & & & & & \\ 0 & \frac{6 E I}{l^{2}} & 0 & 0 & \frac{4 E I}{l^{3}} & & & & & \\ -\frac{E A}{l} & 0 & 0 & 0 & 0 & \frac{E A}{l} & & & & \\ 0 & -\frac{12 E I}{l^{3}} & 0 & 0 & -\frac{6 E I}{l^{2}} & 0 & \frac{12 E I}{l^{3}} & & & \\ 0 & 0 & \frac{12 E I}{l^{3}} & \frac{6 E I}{l^{2}} & 0 & 0 & 0 & \frac{12 E I}{l^{3}} & & \\ 0 & 0 & -\frac{6 E I}{l^{2}} & \frac{2 E I}{l} & 0 & 0 & 0 & \frac{1}{10} & \frac{4 E I}{l^{3}} & \\ 0 & \frac{6 E I}{l^{2}} & 0 & 0 & \frac{2 E I}{l} & 0 & -\frac{6 E I}{l^{2}} & 0 & 0 & \frac{4 E I}{l^{3}}\end{array}\right]$

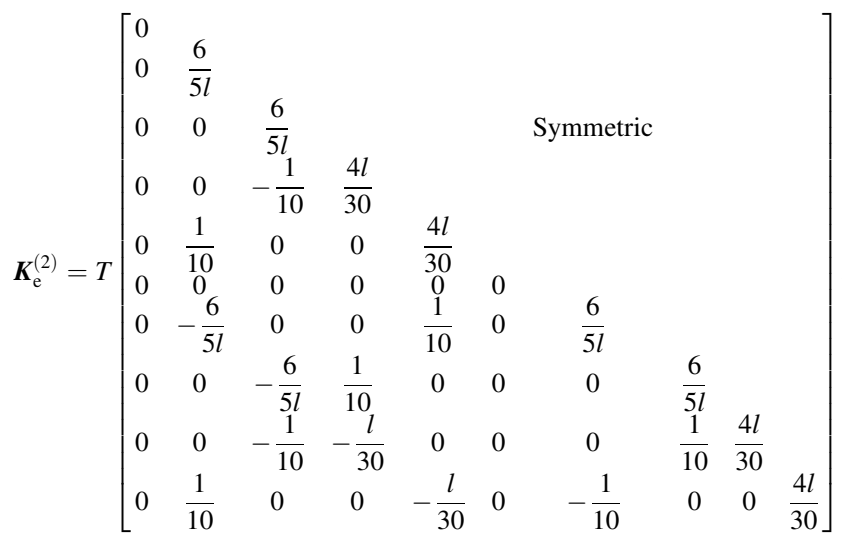

The structural equation of motion can be written as

$\boldsymbol{M}_{\mathrm{g}} \Delta \ddot{\boldsymbol{u}}+\mathbf{C}_{\mathrm{g}} \Delta \dot{\boldsymbol{u}}+\boldsymbol{K}_{\mathrm{g}} \Delta \boldsymbol{u}=\Delta \boldsymbol{F}_{\mathrm{g}}$,

where $\boldsymbol{M}_{\mathrm{g}}$ and $\boldsymbol{C}_{\mathrm{g}}$ are the global mass and damping matrices, respectively; $\Delta \boldsymbol{u}, \Delta \dot{\boldsymbol{u}}$ and $\Delta \ddot{\boldsymbol{u}}$ are the vectors of displacement, velocity and acceleration, respectively, and $\Delta \boldsymbol{F}_{\mathrm{g}}$ is the external force increment matrix.

Generally, the displacement of the contact wire is very small, so the geometrical nonlinearity can be neglected. The dropper is assumed as a nonlinear spring. In numerical examples, the stiffness of dropper is updated in each time step by comparing the initial length with the strained length. So the global stiffness is updated in each time step in Eq. (11). Ambrósio and Pombo [19-27] establish the catenary model by this method and study the pantographcatenary interaction in combination with a pantograph. Simultaneously, Cho et al. [28, 29] establish the catenary model through this method and study the effect of the contact wire sag and nonlinear droppers on the pantograph-catenary behavior by introducing a pantograph model. Stichel et al. [30, 31] construct the catenary model and analyze its interaction with multiple pantographs. 
Bruni et al. [32, 33] construct the hardware-in-the-loop hybrid pantograph platform, in which the catenary is modeled by this method. Massat [34-36] build up the pantograph-catenary model considering the contact wire irregularities and aerodynamic disturbance to pantograph.

When the catenary deforms largely, especially in a highspeed condition or a strong wind field, the geometrical nonlinearity should be considered. In order to ensure the calculation accuracy, the large deformation stiffness matrix should be included. According to the principle of virtual displacement, the equilibrium equation of beam can be written as follows:

$$
\left(\boldsymbol{K}_{\mathrm{e}}^{(1)}+\boldsymbol{K}_{\mathrm{e}}^{(2)}+\boldsymbol{K}_{\mathrm{e}}^{(3)}\right)\left\{\Delta \boldsymbol{D}_{\mathrm{e}}\right\}=\boldsymbol{F}_{\mathrm{e}}-\boldsymbol{Q}_{\mathrm{e}}
$$

where $\Delta \boldsymbol{D}_{\mathrm{e}}$ is the incremental displacement vector; $\boldsymbol{F}_{\mathrm{e}}$ is the equivalent load vector; $\boldsymbol{Q}_{\mathrm{e}}$ is the unbalanced force vector; and $\boldsymbol{K}_{\mathrm{e}}^{(3)}$ is the large deformation stiffness matrix, whose formula is very complex. Generally, the Newmark iteration algorithm is used to solve the equation of motion, Eq. (11), and the Newton-Raphson's method is used to solve Eq. (12).

Carnicero and Lopez-Garcia [37] adopt the nonlinear finite element procedure to establish the catenary model. Then the pantograph-catenary interaction is analyzed with different catenary models [38]. In combination with a vehicle-track model, the effect of random track irregularities on the pantograph-catenary contact force is studied [39]. In order to improve the solution efficiency, Carnicero et al. [40] also propose a moving mesh method for pantograph-catenary model. Compared with the traditional method, the computational cost is significantly decreased. Simultaneously, Mitsuru Ikeda et al. [41-43] propose the detection and control strategy based on a nonlinear finite element catenary. Alberto and Bene [44, 45] neglect the bending stiffness of the messenger/contact wire and develop the 2D and 3D simulation platforms for the pantograph-catenary system.

In order to consider the large deformation further, Park and Kim [12, 13, 46, 47] utilize absolute nodal coordinate formulation (ANCF) beam to model the large deformation of contact/messenger wire. ANCF is firstly proposed by Shabana [48], which can effectively deal with the large deformation of the beam, shell and cable elements. GarcíaVallejo et al. [49] write the formula between the stiffness matrix and the nodal displacements, which is convenient for different engineering applications, as follows:

$$
\begin{aligned}
\boldsymbol{K}_{\mathrm{e}}(\boldsymbol{e})= & \sum_{\alpha=1}^{3} \frac{\chi+2 \delta}{2} \int_{V_{\mathrm{e}}}\left(\boldsymbol{S}_{1}^{\mathrm{T}} \boldsymbol{S}_{1} \boldsymbol{e} \boldsymbol{e}^{\mathrm{T}} \boldsymbol{S}_{1}^{\mathrm{T}} \boldsymbol{S}_{1}-\boldsymbol{S}_{1}^{\mathrm{T}} \boldsymbol{S}_{1}\right) \mathrm{d} V_{\mathrm{e}} \\
& +\sum_{\substack { \alpha=1 \\
\begin{subarray}{c}{\beta=1 \\
\beta \neq \alpha{ \alpha = 1 \\
\begin{subarray} { c } { \beta = 1 \\
\beta \neq \alpha } }\end{subarray}}^{3} \frac{\chi}{2} \int_{V_{\mathrm{e}}}\left(\boldsymbol{S}_{1}^{\mathrm{T}} \boldsymbol{S}_{1} \boldsymbol{e} \boldsymbol{e}^{\mathrm{T}} \boldsymbol{S}_{2}^{\mathrm{T}} \boldsymbol{S}_{2}-\boldsymbol{S}_{1}^{\mathrm{T}} \boldsymbol{S}_{1}\right) \mathrm{d} V_{\mathrm{e}} \\
& +\sum_{\alpha=1}^{3} \sum_{\substack{\beta=1 \\
\beta \neq \alpha}}^{3} \delta \int_{V_{\mathrm{e}}}\left(\boldsymbol{S}_{1}^{\mathrm{T}} \boldsymbol{S}_{1} \boldsymbol{e} \boldsymbol{e}^{\mathrm{T}} \boldsymbol{S}_{2}^{\mathrm{T}} \boldsymbol{S}_{2}-\boldsymbol{S}_{1}^{\mathrm{T}} \boldsymbol{S}_{2}\right) \mathrm{d} V_{\mathrm{e}},
\end{aligned}
$$

where $\chi$ is the Lame constant, $\delta$ is the shear elasticity of the beam, $V_{\mathrm{e}}$ is the volume of the element, $\boldsymbol{S}_{1}$ and $\boldsymbol{S}_{2}$ are the shapefunction matrices, and $\boldsymbol{e}$ is the vector of coordinates of the two nodes of beam. Each node has 12 DOFs, which can fully consider various kinds of deformation. After obtaining the displacement vector, the stiffness matrix can be generated through Eq. (13), so that the large deformation can be considered.

Similarly, in order to consider the large deformation of contact wire, Refs. $[15,16]$ neglect the bending stiffness and propose a catenary model based on flexible cable and nonlinear truss elements. As shown in Fig. 5, A and B are the two nodes of the flexible element. $F_{1}-F_{6}$ are the nodal forces, $L_{0}$ is the initial length; $l_{x}, l_{y}$ and $l_{z}$ are the interval between $\mathrm{A}$ and $\mathrm{B}$ in $x, y$ and $z$ directions; $T_{1}$ and $T_{2}$ are the tensile forces. The equilibrium equation can be expressed as

$$
\left\{\begin{aligned}
l_{x}= & \frac{F_{1} L_{0}}{E A}+\frac{F_{1}}{p}\left\{\ln \left(\sqrt{F_{4}^{2}+F_{5}^{2}+F_{6}^{2}}+F_{6}\right)\right. \\
& \left.-\ln \left(\sqrt{F_{1}^{2}+F_{2}^{2}+F_{3}^{2}}-F_{3}\right)\right\}, \\
l_{y}= & \frac{F_{2} L_{0}}{E A}+\frac{F_{2}}{p}\left\{\ln \left(\sqrt{F_{4}^{2}+F_{5}^{2}+F_{6}^{2}}+F_{6}\right)\right. \\
& \left.-\ln \left(\sqrt{F_{1}^{2}+F_{2}^{2}+F_{3}^{2}}-F_{3}\right)\right\} \\
l_{z}= & \frac{F_{3} L_{0}}{E A}+\frac{p L_{0}^{2}}{2 E A}+\frac{1}{p} \\
& {\left[\sqrt{F_{4}^{2}+F_{5}^{2}+F_{6}^{2}}-\sqrt{F_{1}^{2}+F_{2}^{2}+F_{3}^{2}}\right], }
\end{aligned}\right.
$$

where $p$ is the self-weight per unit length. The stiffness matrix can be generated through differentiation of the two sides of Eq. (14):

$$
\left\{\begin{array}{l}
\mathrm{d} l_{x} \\
\mathrm{~d} l_{y} \\
\mathrm{~d} l_{z}
\end{array}\right\}=\left[\begin{array}{lll}
\frac{\partial l_{x}}{\partial F_{1}} & \frac{\partial l_{x}}{\partial F_{2}} & \frac{\partial l_{x}}{\partial F_{3}} \\
\frac{\partial l_{y}}{\partial F_{1}} & \frac{\partial l_{y}}{\partial F_{2}} & \frac{\partial l_{y}}{\partial F_{3}} \\
\frac{\partial l_{z}}{\partial F_{1}} & \frac{\partial l_{z}}{\partial F_{2}} & \frac{\partial l_{z}}{\partial F_{3}}
\end{array}\right]\left\{\begin{array}{l}
\mathrm{d} F_{1} \\
\mathrm{~d} F_{2} \\
\mathrm{~d} F_{3}
\end{array}\right\}=\boldsymbol{G}_{\mathrm{C}}^{\mathrm{e}} \mathrm{d} \boldsymbol{F}^{\mathrm{e}},
$$

where $\boldsymbol{G}_{\mathrm{C}}^{\mathrm{e}}$ is the flexibility matrix, and $F^{\mathrm{e}}$ is the element nodal force vector. The stiffness matrix can be obtained by taking inverse of it. Similar to ANCF, Eq. (15) establishes the relationship between the stiffness matrix and the nodal 


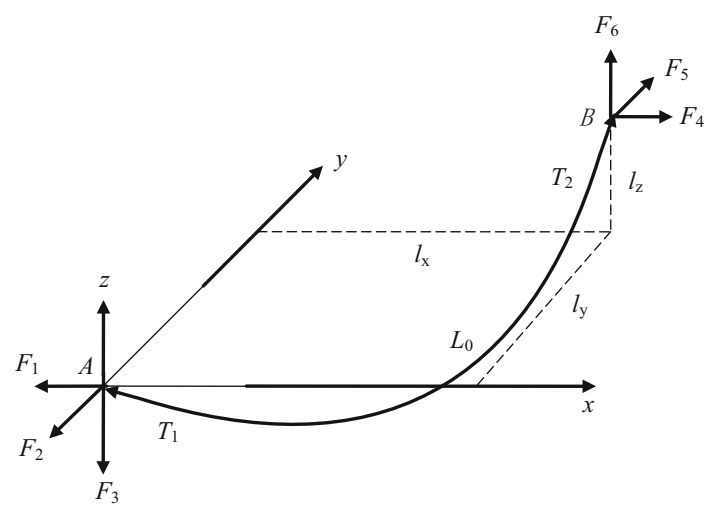

Fig. 5 Flexible cable element

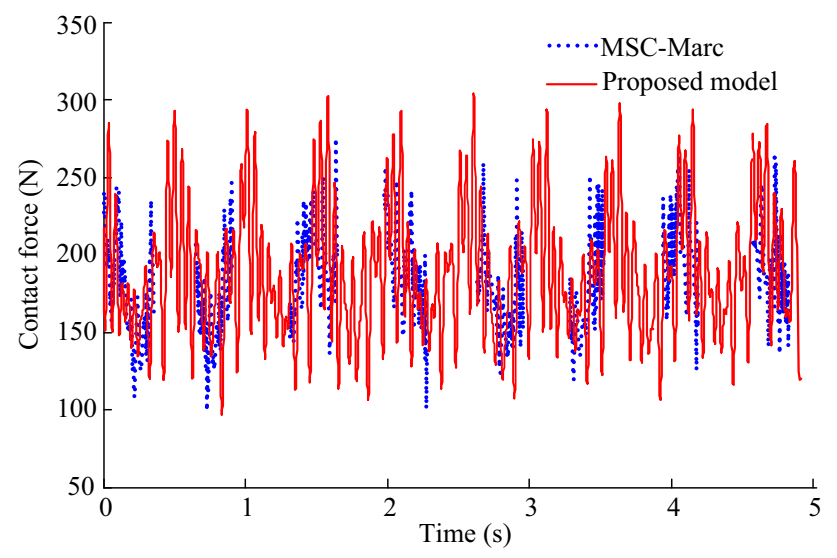

Fig. 6 Comparison in computation results of contact force between MSC Marc and flexible cable model

displacement. Through Newton-Raphson's method, the nodal forces can be calculated. Thus the stiffness matrix of each element can be produced. Figure 6 compares the results between this method and the FEM software. It can be seen that only a little difference exists in the two sets of result.

\subsubsection{Modal superposition method}

In order to overcome the huge computation cost and the low efficiency of the traditional finite element model, modal superposition method is used to establish the equation of motion for catenary. Generally, a FEM model is necessary to be established and then the modal analysis is conducted. The displacement of catenary is described as the summation of all modes:

$z(x, t)=\sum_{i=1}^{n} \phi_{i}(x) q_{i}(t)$ where $\phi_{i}(x)$ is the $i$ th mode, $q_{i}(t)$ is the $i$ th generalized coordinate, and $n$ is the total order of modes.

Considering the orthogonality of the main vibration mode, the equation of motion can be obtained as

$m_{i i} \ddot{q}_{i}+2 m_{i i} \omega_{i i} \xi_{i} \dot{q}_{i}+m_{i i} \omega_{i i}^{2} q_{i}=Q_{i}(t) \quad(i=1,2,3, \ldots, n)$,

where $m_{i i}, \omega_{i i}, \xi_{i}$ and $Q_{i}(t)$ are the $i$ th modal mass, angular frequency, damping ratio and generalized force, respectively. Through Newmark iteration method, Eq. (17) can be solved. Then the actual displacement of catenary can be obtained through Eq. (16). Reference [50] indicates that the modal order should be above 180 to guarantee a good accuracy. Using this method, Refs. [51, 52] analyze the catenary response and stress under the impact of pantograph and develop a hardware-in-the-loop, in which the catenary is modeled by modal superposition method $[53,54]$.

Through the above discussion, it is found that the FEM is the most prevalent method to model the catenary dynamic behavior. One of the future developments is to accurately describe the nonlinearity of catenary wires. The modal superposition method and finite difference method can be adopted when a fast solution speed is required. On the other hand, considering more realistic conditions is another research interest for many scholars. Reference [55] proposes a rigid catenary modeling method. Rigid catenaries are mainly used in tunnels, whose structure is much simpler than the flexible catenary. Reference [56] proposes the modeling method for the overlap section. And the contact wire irregularities are introduced in the catenary model $[57,58]$.

\subsection{Effect of wind load on catenary}

In normal operations, railway catenary is very sensitive to wind load because of its long-span and high flexibility. The wind load is normally divided into two types: steady wind and stochastic wind. Steady wind is not varying with time. And stochastic wind varies with time and spatial position. Under low-frequency and time-varying stochastic wind load, the catenary can produce a forced vibration, which is called buffeting. Under steady wind loads, the catenary can often produce wind deviations with vortex-induced vibration. The vortex-induced vibration is caused by the wind flowing around slim cylinder as shown in Fig. 7 [59].

Reference [60] has done a detailed investigation on this issue. Through exerting the vortex-induced forces on the catenary model, the effect of wind velocity on the vortexinduced vibration amplitude is analyzed. The results indicate that the vortex-induced vibration for catenary is not very large, and cannot produce huge detriment for 


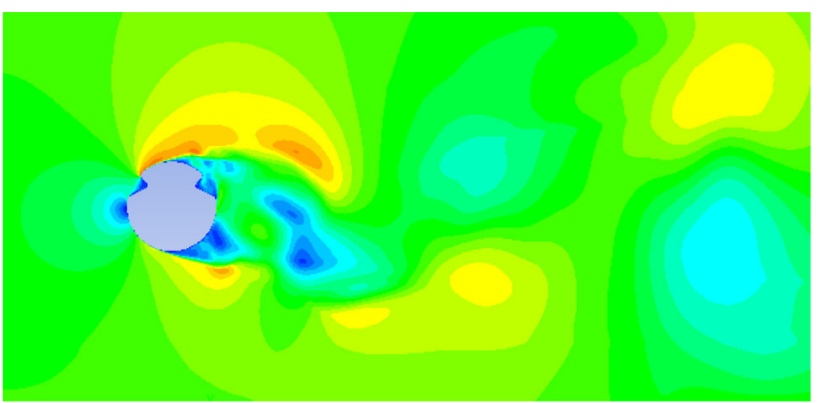

Fig. 7 Karman vortex street of catenary [59]

pantograph-catenary current collection quality. For the effect of steady wind load, Ref. [59] derives the aerodynamic damping acting on contact wire as:

$C_{\text {air }}=\left.\frac{1}{2} \rho_{\text {air }} U D\left(\frac{\mathrm{d} C_{\mathrm{L}}(\alpha)}{\mathrm{d} \alpha}+C_{\mathrm{D}}(\alpha)\right)\right|_{\alpha=0}$,

where $\rho_{\text {air }}$ is the air density, $U$ is the steady wind velocity, $D$ is the diameter of the contact wire cross section, and $C_{\mathrm{L}}$ and $C_{\mathrm{D}}$ are the lift and drag coefficients. The results indicate that the aerodynamic damping is very small and cannot largely affect the dynamic behavior of catenary.

The lift coefficient $C_{\mathrm{L}}$ and drag coefficient $C_{\mathrm{D}}$ are determined by the wind tunnel experiment or computational fluid dynamics (CFD). Reference [61] adopts wind tunnel experiment to calculate the aerodynamic coefficients under horizontal wind load and establishes a CFD model for the contact wire cross section. The accuracy is verified by comparing the results obtained by the two methods. References [9, 62] establish a 2D CFD model for the contact wire considering more angles of attack, and the iced contact wire is also analyzed. Reference [63] measures the aerodynamic coefficients of contact wire cross section and calculated the Den Hartog coefficient. The instability region is determined at around the angle of attack $\pm 35^{\circ}$, which may cause the negative damping of catenary and lead to a rare galloping with huge amplitude. The galloping of catenary can cause destructive damage to the catenary structure. By observing the iced line in wind tunnel, Xie et al. [64] find that the instability region may be enlarged. Until now, such a rare phenomenon has not been realized by numerical simulation, and the mechanism of catenary galloping is not fully clear yet [65].

In order to describe the fluctuating forces caused by stochastic wind load, the time histories of stochastic wind velocity should be generated. The harmonic superposition method, AR model method and wavelet reconstruction method are well used to generate the time histories of fluctuating wind velocity. Reference [66] gives a detailed summary for the three kinds of method. Pombo et al.

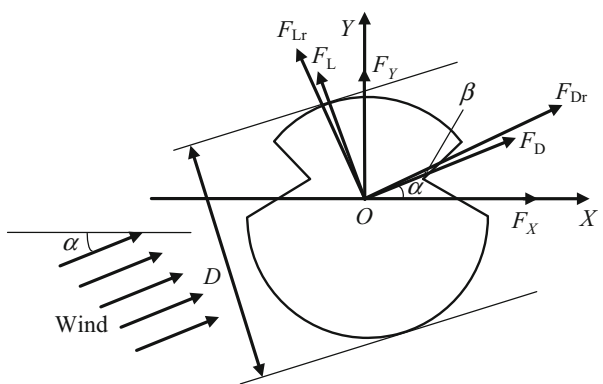

Fig. 8 Upwind section of contact line

[67, 68] adopt the Karman spectrum to generate the fluctuating wind velocities in lateral and vertical directions. The aerodynamic forces acting on catenary are calculated through the following equations:

$\left.\begin{array}{rl}F_{\mathrm{L}} & =\frac{1}{2} \rho_{\text {air }} U^{2} D L C_{\mathrm{L}} \\ F_{\mathrm{D}} & =\frac{1}{2} \rho_{\text {air }} U^{2} D L C_{\mathrm{D}}\end{array}\right\}$,

where $F_{\mathrm{L}}$ and $F_{\mathrm{D}}$ are the lift and drag acting on contact wire, and $L$ is the length of cable. Through exerting the aerodynamic force in Eq. (19) on catenary, the effect of stochastic wind load on current collection quality can be investigated. But in Pombo et al.'s work, the angle of attack is not considered. References [69, 70] adopt the formula of wind pressure in relevant standards as the excitation on the catenary, and the wind-induced vibration and its effect on pantograph-catenary interaction are investigated. The expression of wind pressure can be written as

$F=\frac{1}{1600} \beta_{z} u_{\mathrm{s}} u_{z} A_{\mathrm{w}}[U(x)+v(x, t)]^{2}$,

where $\beta_{z}$ is the wind vibration coefficient, $u_{\mathrm{s}}$ is the wind load shape coefficient, $u_{z}$ is the wind pressure varying coefficient, $A_{\mathrm{w}}$ is the windward area of the structure, $U(x)$ is the steady wind velocity, and $v(x, t)$ is the fluctuating wind velocity.

Reference [71] also adopts such an aerodynamic force model to study the wind-induced vibration response and analyzes the fatigue of contact wire under wind load. But this method neglects the fluctuating wind in vertical direction and cannot consider the cross section of contact wire. Reference [72] proposes a new fluctuating wind force model considering the irregularity of contact wire cross section. The contact wire cross section under wind load is shown in Fig. 8. The fluctuating wind model can be written as 


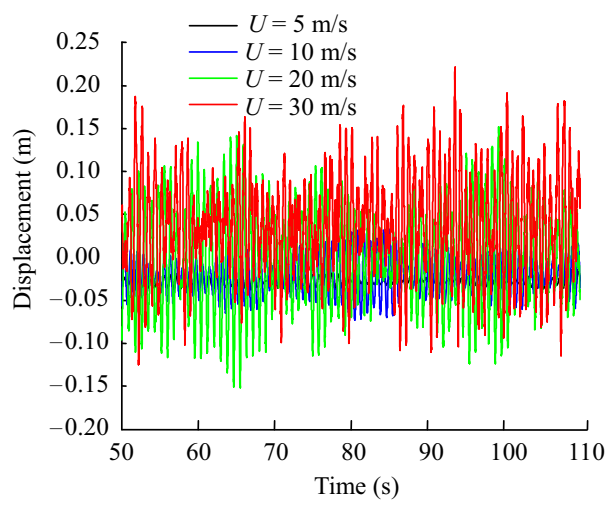

(a) Attack angle $\alpha=40^{\circ}$

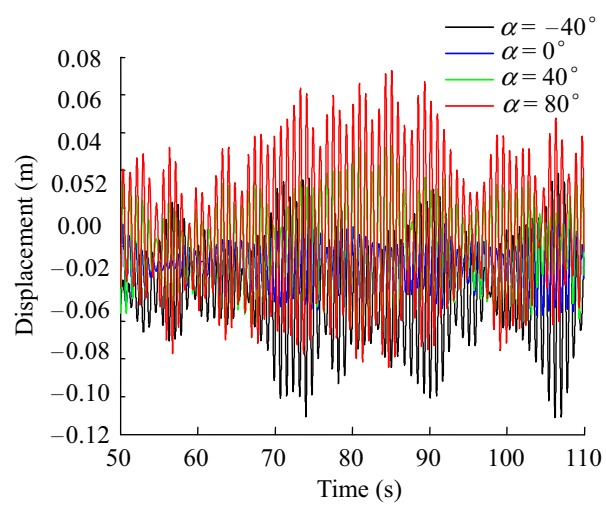

(b) Wind velocity $U=10 \mathrm{~m} / \mathrm{s}$

Fig. 9 Contact line vertical vibration responses under different wind velocities (a) and attack angles (b)

$$
\begin{aligned}
F_{\mathrm{D}}= & \frac{1}{2} \rho_{\text {air }} U^{2} L D\left[C_{\mathrm{D}}\left(\alpha_{0}\right) \frac{2 u(t)}{U}+\left[\dot{C_{\mathrm{D}}}\left(\alpha_{0}\right)-C_{\mathrm{L}}\left(\alpha_{0}\right)\right] \frac{w(t)}{U}\right] \\
& +\frac{1}{2} \rho_{\text {air }} U^{2} D L C_{\mathrm{D}}\left(\alpha_{0}\right),
\end{aligned}
$$

$$
\begin{aligned}
F_{\mathrm{L}}= & \frac{1}{2} \rho_{\text {air }} U^{2} L D\left[C_{L}\left(\alpha_{0}\right) \frac{2 u(t)}{U}+\left[\dot{C}_{\mathrm{L}}\left(\alpha_{0}\right)+C_{\mathrm{D}}\left(\alpha_{0}\right)\right] \frac{w(t)}{U}\right] \\
& +\frac{1}{2} \rho U^{2} D L C_{\mathrm{L}}\left(\alpha_{0}\right),
\end{aligned}
$$

where $u(t)$ and $w(t)$ are the fluctuating wind in verticalwind and along-wind directions. Converted into the bodyaxis coordinate system, the above model can be expressed as

$$
\left.\begin{array}{l}
F_{X}=F_{\mathrm{D}} \cos \alpha_{0}-F_{\mathrm{L}} \sin \alpha_{0} \\
F_{Y}=F_{\mathrm{D}} \sin \alpha_{0}+F_{\mathrm{L}} \cos \alpha_{0}
\end{array}\right\} .
$$

Equation (22) is the aerodynamic forces which can be used in FEM model directly. By exerting the buffeting forces on catenary, the wind-induced vibration behavior can be simulated. Figure 9 shows the vertical vibration response with different angles of attack and wind velocities. It can be seen that not only the wind velocity, but also the angle of attack are the critical factors influencing the wind-induced vibration behavior of catenary. Figure 10 shows the contact force of pantograph-catenary with different angles of attack and wind velocities. It can be seen that the increase in the wind velocity can lead to a more severe vibration of the catenary. The increase in attack angle toward a vertical direction can also deteriorate the current collection quality of pantograph-catenary system. Based on this method, Ref. [73] analyzes the wind-induced vibration response with iced contact wire. The results indicate that the aerodynamic coefficients $C_{\mathrm{L}}$ and $C_{\mathrm{D}}$ are changed by the ice covering the contact line, which may influence the wind-induced vibration behavior. Reference [74] develops a spatial wind field along the catenary and conducted the sensitivity analysis of the structural parameters on the wind-induced vibration behavior of the catenary.

\section{Catenary non-contact detection}

Non-contact detection methods based on image processing techniques are able to detect multiple catenary fittings using a single device at a less cost compared to the traditional detection method. Image-based non-contact catenary detection has become a hot area of research. By analyzing the catenary fittings using intelligent image identification algorithms, the image-based non-contact catenary methods are able to detect geometry parameters of pantographs and catenaries, as well as to recognize the faults of the pantograph-catenary system [75]. The term 'fault recognition' in this paper means the identification of a pre-defined feature that can be used as the basis of judging the existence of a specific fault in the process of fault diagnosis.

\subsection{Detecting the geometry parameters of catenary system}

The geometry parameters of catenary system include contact wire height, stagger, trolley frog, etc. These parameters are crucial indicators for evaluating the quality of the current collection of locomotives. Application of portable laser measuring devices is the commonest method for measuring the static geometry parameters of catenary system. However, when operating the portable laser 


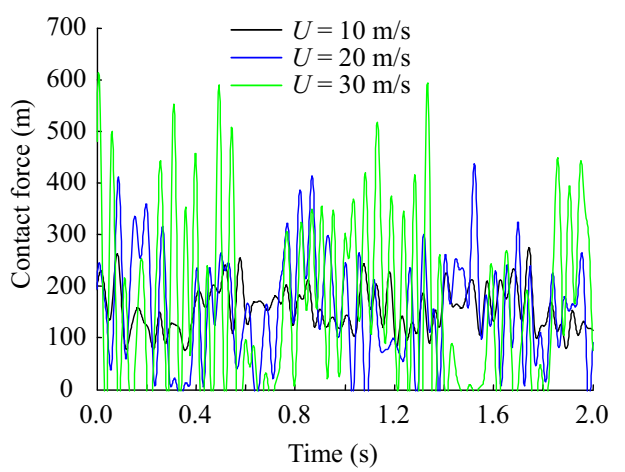

(a) Attack angle $\alpha=70^{\circ}$

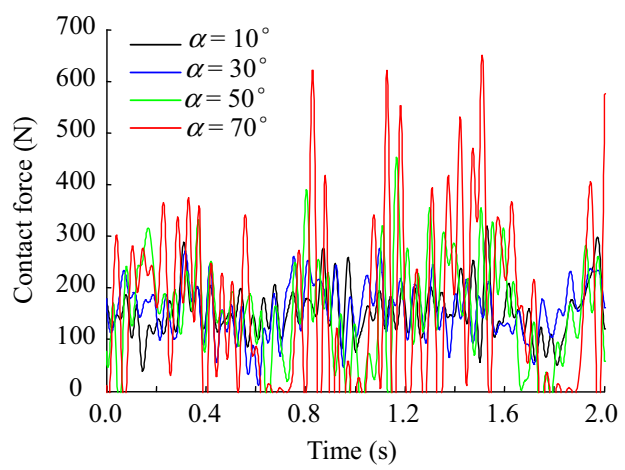

(b) Wind velocity $U=30 \mathrm{~m} / \mathrm{s}$

Fig. 10 Contact force under different wind velocities (a) and attack angles (b) (train speed is $325 \mathrm{~km} / \mathrm{h}$ )

measuring devices, measuring points need to be selected and the device itself needs to be calibrated. Thus they are not capable of obtaining the geometry parameters of the catenary system for the whole line in a short time. To address this shortcoming, in [76], a stagger computing method based on the measurement result of the contact force was derived. The model of the system was established using neural network models and the adaptive neural network fuzzy reasoning algorithm. The effectiveness of this method was verified by simulation analysis. In [77], two CMOS cameras symmetrically mounted on the locomotive were used to collect images of the catenary. The contact wire height and stagger were measured by determining the frontier points of the abrasion surface of the contact wire using edge detection algorithms. Compared with the method of computing the stagger from the contact force, this method has a higher reliability. In [78], the slide plates of the pantograph and the characteristic values of the contact wire were extracted from a video of the pantograph-catenary system. The contact wire height and stagger were computed based on the displacement of slide plates. In [79], based on the imaging characteristics of the pantograph and the contact wire, the pantograph and the contact wire were recognized in the image successively. The contact wire height and stagger were computed based on the calibration of the camera. In [80], an industrial camera mounted on the roof of an inspection vehicle was used to capture the reflection ray of a laser emitter. In this way, geometry parameters of the catenary system, such as the contact wire height and stagger, can be dynamically monitored. To increase the measurement frequency of dynamic catenary parameter measurement devices while guaranteeing the measurement accuracy, the computational formula of binocular linear array active camera measurement was derived in [81]. A nonlinear vision measurement model of the geometric parameters of the catenary system was also established, which can greatly improve the speed of dynamic measurement of catenary geometry parameters. Based on the theory of binocular vision photogrammetry, two HD cameras were used to acquire image features for measurement in [82], and image processing and three-dimensional analytical computations were then utilized. This method could achieve the real-time measurement of catenary geometry parameters, with a repeatability accuracy of less than $1 \mathrm{~mm}$. In [83, 84], images of the catenary system were captured by a single camera mounted on the top of a tower wagon. The contact wire height and stagger were computed based on the localization of the contact wire using image processing techniques. Vibration compensation is a crucial problem during the measurement of catenary geometry parameters. When the inspection vehicle is running, due to the vehicle vibration, the horizontal displacement of the vehicle body relative to the track center and the vertical displacement relative to the rail surface will cause non-negligible errors in the measurement. In addition, because of the idling and sliding of the wheel, cumulative errors in localization will be generated. These errors will continuously increase as the detection distance increases. The measurement result will finally lose efficacy due to these errors. To solve this problem, in [85], the compensation formula of the geometry parameters was derived from the transformation between the world coordinate system and the image coordinate system. The Kalman filtering equations were set up based on the geometry modal of catenary system, and the correction of geometry parameters catenary system was made. In [86], a pair of laser sensors for imaging was mounted on the bottom of the inspection vehicle and was used to obtain the images of both the two sides of the rail. In the process of static measurement, feature points of the rail gauge were 
extracted using digital image processing techniques. The horizontal and vertical distances between each camera and the rail gauge point on the adjacent side of the rail were considered as the static calibration of the measurement. In the process of dynamic measurement, the rail gauge points were extracted in real time and the displacements of the cameras relative to the rail gauge points were obtained. These displacements were compared with the displacements obtained in static calibration, so the offset caused by the vibration of the vehicle can be measured. Meanwhile, the feature points of the catenary system along the railway, such as the registration tubes, cantilevers and anchoring sections, were recognized using computer vision techniques. So the cumulative errors can be eliminated when the vehicle passes a registration tube or an insulation joint of the rail. In [87], the lens distortion of the camera was considered in the calibration achieved by using laser sensors mounted on the bottom of the vehicle. A nonlinear model of the camera was established, and the calibration of the camera was achieved by using the coplanar calibration method based on the least square method. The algorithm of computing the vibration compensation was derived using computer vision techniques and can achieve promising experimental results.

\subsection{Detecting the slope of steady arm}

For the detection of the slope of steady arms, analyzing images of steady arms captured by cameras mounted on the top of a vehicle using image processing techniques have become a method that receives more and more attention in practice. In [88], chain code was firstly used to approximately localize the target segments and to calculate the inclination angles. Then Radon transformation was used to precisely localize the target segments. This method can realize a fast and accurate detection of the target segments. In [89], a fast corner point detection method based on fuzzy decision trees was proposed and the computation speed was improved. In [90], the corner point matching algorithm was used to match the corner points extracted in the image sequence that needs to be detected, and the slope of the steady arm can be dynamically obtained by using the affine invariant line matching algorithm. Using this method, the uncertainty of the measuring result can be decreased. In [91, 92], the steady arms in the image were transformed to segments by image thinning. Then based on the Hough transformation theory, features of the segments were observed in the polar coordinate system and the slope of the steady arm was computed. In [93], the segments in the image are extracted using Hough transform, and then the AdaBoost algorithm was used to identify the steady arm in an area that was roughly determined in object localization. The methods mentioned above all have high practical values and can be used to replace the traditional manual detection method.

\subsection{Detecting the abrasion of contact wire}

The most commonly used abrasion detection methods for contact wires include image detection, laser scan and residual height measurement. The image detection method uses a row of cameras that have overlapping visual fields to cover the whole range of the stagger and adopts several parallel data acquisition and data processing channels. This method is relatively easy to realize [94].

In [95], the structure and principle of linear chargecoupled device (CCD) arrays were introduced and the applications of linear CCD arrays in abrasion detection were summarized. The MEDES system from Spain, ATON system from Netherlands, WWS system from Germany and WIRECHECK system from Italy all adopt light sources to illuminate the abrasion surface of contact wire and use high-speed cameras to capture the image of the contact surface. The width of the abrasion surface is then obtained by hardware processing and software image processing and the abrasion can be measured in real time. The images of the abrasion surface of contact wire may have problems such as low resolution and blurring edges. In order to solve problems like these, in [96], a sub-pixel edge detection method was proposed to extract the edge of the abrasion surface and to measure the abrasion of the wire. This method was a combination of the zero-crossing method and the quadratic curve fitting method. In [97], curvelet transformation was used to enhance the image of the abrasion surface of contact wires.

\subsection{Detecting the wind deviation of contact wire}

Compared with the geometry parameters of catenary, the wind deviation of contact wire is more difficult to measure. Currently only a research team in Central South University developed a real-time ground catenary wind-deviation posture detection method that can be used in windy regions $[98,99]$. Their methods adopted the first-order brightness moment optimizing algorithm based on contrast stretching to achieve accurate and effective segmentation of the object feature points in color images captured in different illumination conditions. A deviation and torsion feature extraction method for moving objects was constructed based on the area method and the geometry method. Through static and dynamic feature points matching on the objective target plane and the observation of movement compensation for benchmark instability, the three-component motion detection (lateral displacement, wind deviation of uplifting and torsion angle) of catenary suspension 
structure was realized, including the contact wire, messenger wire and dropper.

\subsection{Detecting the abnormal working status of catenary fittings}

Because of the growing tension of the contact wire and messenger wire, and the influence of operation environment, the strain and vibration of catenary fittings are also increasing. Thus the safety problem of catenary fittings is highlighted. Many researchers have developed automatic recognition methods and fault detection methods for different types of catenary fittings. In [100], the effective value and standard deviation of the leakage current were considered as the feature value in contamination detection, based on the grey relational analysis between the environmental factor and the leakage current. In [101], templates of the catenary fittings were firstly created. These templates were consulted when recognizing the fittings in the detection phase. Then the geometrical morphology analysis of the extracted fittings was performed and the fittings with abnormalities can be found. In [102], the localization of the insulators was achieved by template matching and analyzing the characteristics of the reflected ray. The foreign object between the insulator ceramic disks was detected using the singularity of wavelet coefficients. In [103], directional filtering was achieved using curvelet. Then, the clustered coefficients of curvelet were enhanced using mathematical morphology. Finally, the insulators were localized by processing the curvelet coefficients using the zonal energy statistical method. In [104], six different affine invariant moments were used to localize the insulator. The edges of the insulator were enhanced by dilation. Then the foreign object was detected by using grayscale parameter statistics. In [105], Harris corner points and spectral clustering were combined to achieve anti-rotation insulator matching and fault detection. In [106-109], the detection of clevises and insulators was achieved by feature matching, scale-invariant feature transform (SIFT) and speeded-up robust features (SURF). The abnormal working status of these fittings was detected by analyzing the edge information and grayscale statistical information. Machine learning methods based on local features have shown promising results in catenary fitting fault detection. In [110-112], local features such as histogram of oriented gradients (HOG) were processed with pattern recognition methods including support vector machine (SVM) and cascaded AdaBoost. Fittings such as clevis, diagonal tube and messenger wire bracket were successfully detected in the image, as shown in Fig. 11a-c. Fault detection was then accomplished based on the results of fitting detection.

\subsection{Detecting foreign objects in catenary system}

Foreign objects suspended in the catenary system will cause problems such as hitting the pantograph or hauling the contact wire, which may lead to serious consequences. Therefore, the pantograph needs to be lowered in advance. For example, if the branches of a tree enter the movement range of the pantograph and train body, accidents will be easily caused to the catenary and pantograph. The application of computer vision can effectively reduce the workload of searching along the railway line. Thus the efficiency of maintenance can be increased and faults can be discovered in time. In [113], three-dimensional reconstruction and model matching were used to process images captured by a binocular camera. This method detected the foreign object successfully, but would take a relatively long time. In [114], the edge detection method was used to detect the edges of the objects in the image. When a potential foreign object was detected, SVM was used to perform feature classification and to determine whether it was a foreign object. In $[115,116]$, real-time object positioning and tracking methods based on background
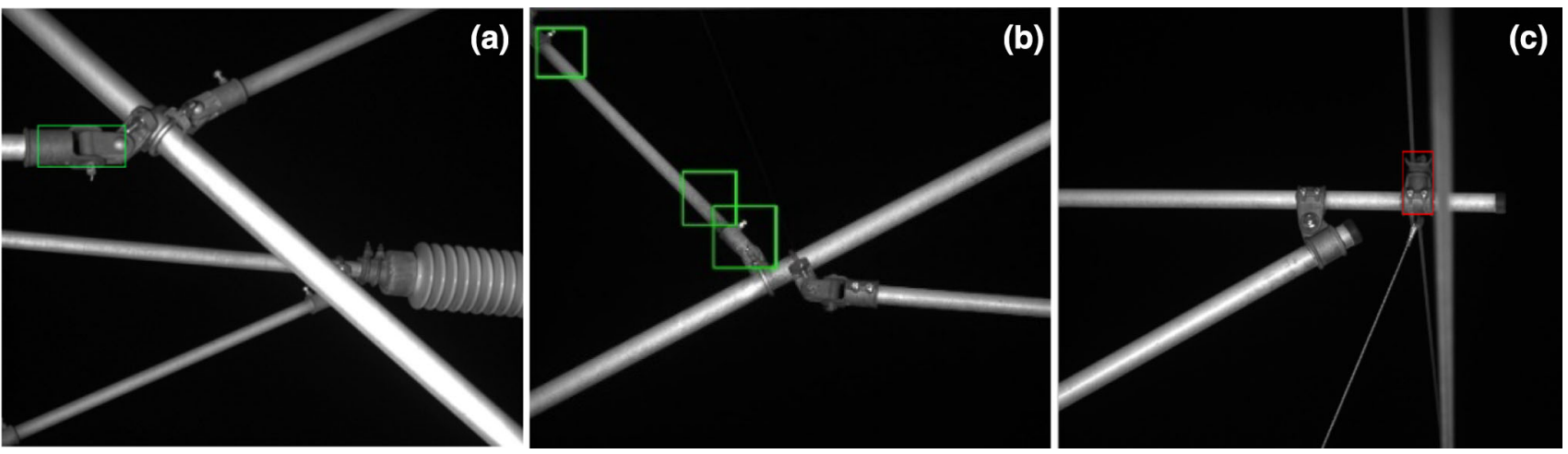

Fig. 11 Identification and location of catenary key components: a clevis; $\mathbf{b}$ diagonal tube; $\mathbf{c}$ messenger wire bracket 
difference were studied. Foreign objects were recognized by analyzing their motion curves. In [117], a catenary foreign object and electric arc detection method was proposed. This method first used mean-shift method to track the contact wire in the video. Then the foreground was detected using the Gaussian mixture model. By doing this, the foreign object or the electric arc can be detected. In [118], Bayesian model was used to inspect the 'high risk' area around the mast and cantilever of the catenary. The tree branches or bird nests entering the range of the catenary can be detected. In [119], affine geometry principle was used to create the detection model of the gradually changing foreign object and. Radon transform was used to monitor the rail. Gradually changing foreign objects that enter the range of the catenary can then be detected. In [120], SVM and Kalman filtering algorithm were combined to realize the classification and tracking of the foreign object.

In short, the catenary non-contact detection methods based on image processing are widely applied in highspeed railway catenary maintenance. Because of the complex operating environment and rigorous operating condition of high-speed railway system, the existing detection methods cannot completely meet the requirement of catenary maintenance and fault detection. With the development of image processing and computer vision, more advanced detection technologies will be used in high-speed railway catenary detection.

\section{State evaluation of catenary system}

The state evaluation of a catenary system refers to characterizing, both qualitatively and quantitatively, the applicability of the catenary to the normal operation of a railway line by utilizing relevant measurement and simulation data. The state evaluation can be applied in all stages of the catenary system including design, acceptance and operation. This evaluation not only estimates the global and long-term state of the catenary system, but also considers the influences of local catenary defects. Another related concept is the defect diagnosis of catenary system, which means diagnosing certain types of catenary defects and their severity based on relevant measurement data, mostly after the catenary system is put into service. These defects directly influence the catenary performance. Thus, the results of catenary defect diagnosis are also included in the state evaluation of catenary system.

\subsection{State evaluation methods for catenary system}

The catenary state evaluation is performed based on the measurement data of the catenary system structure and the interaction between pantograph and catenary. When the catenary system is static without the pantograph, the geometric parameters of contact wire, including the height, stagger and thickness and the simultaneous location information are basic static measurement data. With the contact of pantograph, the dynamic measurement data of catenary system mainly include the contact force between pantograph and catenary, the pantograph vertical acceleration, the vertical displacement of contact wire and pantograph, the frequency of arcing occurrences, etc. Both static and dynamic measurement data can be employed for catenary state evaluation, respectively, for static and dynamic state evaluations [121].

Normally, the static and dynamic state evaluations should be combined for catenary state evaluation. However, because the conventional speed lines usually have low requirements for dynamic measurement data, the static state evaluation is the dominant way to assess their catenary state in practice. Based on static data that are easy to measure and indicators that are easy to calculate, long-term catenary state evaluation has proven effective for in conventional speed lines. Due to the technical difficulty and high cost of performing the dynamic state evaluation, most conventional speed lines only employ dynamic data at the acceptance stage but not during the operation stage. However, as the train speed increases, the static state evaluation becomes insufficient for the operation and maintenance of high-speed lines. Since dynamic state evaluation is based on dynamic data that directly reflect the dynamic interaction, it is more applicable for catenary state evaluation compared with static state evaluation. Thus, related measurement and evaluation techniques have been developed in recent years to meet the emerging needs, making the dynamic state evaluation promising and popular for high-speed railway lines. Meanwhile, to improve the effect and reduce the cost of dynamic state evaluation, a shorter inspection interval [122] and a higher sampling frequency [123] than that in current practice are necessary and helpful.

\subsection{Static state evaluation of catenary system}

In the static state evaluation of high-speed catenary system, the static measurement data describe the spatial location and wear pattern of the contact wire. The current spatial location of contact wire, reflected by measurements of height and stagger, indicates the degree of deviation from the nominal position. The deviation is unfavorable for current collection if is too high and must be fixed if higher than a pre-defined threshold. Similarly, the contact wire must be partly or entirely replaced if the wire thickness is too low. With higher operation speed, the influence caused by deviated wire location and wear will be more 


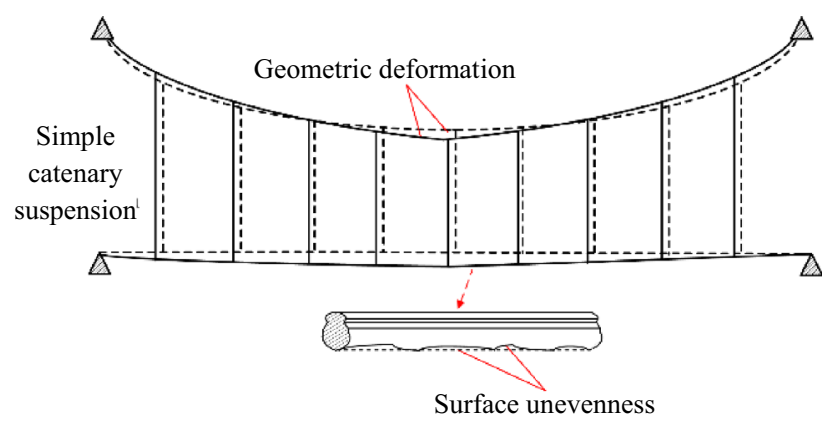

Fig. 12 Sketch of contact wire irregularity

significant. This prompted the proposal of the contact wire irregularity (or unevenness), a concept that describes the state of contact wire geometry. Figure 12 depicts the sketch of contact wire irregularity that is mainly composed of the geometrical deformation and lower surface unevenness of contact wire.

The concept of contact wire irregularity has been gaining attention worldwide since it was first proposed around 2000 [57, 124]. Collina et al. [125] analyzed the influences of contact wire irregularity on the current collection based on in situ measurements combining with simulation results. The pantograph vertical acceleration is employed to reflect and diagnose the state of contact wire irregularity. Based on a specialized test rig, the model for contact wire wear prediction was proposed in [126]. Van et al. [34] investigated impacts of the geometric irregularity and the wear of contact wire, respectively, on pantograph-catenary interaction using simulation. Bohol and Houmei [127] analyzed the wave-like wear pattern measured from the Shinkansen in Japan and its correlation with contact loss. Aboshi et al. $[124,128]$ established the power spectral density (PSD) of the contact wire irregularity of the Shinkansen and analyzed the pantograph-catenary contact force affected by the irregularity. Zhang et al. [54] studied the influence of contact wire irregularity on the contact force using a hardware-in-the-loop test rig and synthetic wire height and identified some critical irregularity wavelengths. Huan et al. [129] discussed the contact wire irregularity measured from the high-speed railway lines in China and analyzed its influence on pantograph-catenary interaction through simulations. Xie et al. [130] also studied the pantographcatenary dynamics when the contact wire irregularity is introduced to the simulation model. In these previous studies, the PSD is the primary method for the characterization of contact wire irregularity. The PSD of contact wire irregularity is mainly evaluated by the traditional periodogram method or maximum entropy evaluation. For a discrete stochastic process with a number $N$ of samples $x(0), x(1), \ldots, x(N-1)$, the periodogram method firstly performs the Fourier transform:

$X(\omega)=\sum_{n=0}^{N-1} x(n) \mathrm{e}^{-\mathrm{j} \omega n}$.

Then, the corresponding PSD is computed as

$P_{x}(\omega)=\frac{1}{N}|X(\omega)|^{2}=\frac{1}{N}\left|\sum_{n=0}^{N-1} x(n) \mathrm{e}^{-\mathrm{j} \omega n}\right|^{2}$.

To overcome the spectral leakage problem caused by traditional methods, Liu et al. [131] proposed the concept of catenary spectrum learning from the track spectrum and applied the autoregressive (AR) spectrum to the PSD of contact wire irregularity [132]. The AR model is defined as

$\sum_{k=0}^{p} a_{k} x(n-k)=w(n)$,

with the AR spectrum computed by

$S\left(\mathrm{e}^{\mathrm{j} \omega}\right)=\frac{\sigma_{w}^{2}}{\left|1+\sum_{k=0}^{p} a_{k} \mathrm{e}^{-|\mathrm{j} \omega k|}\right|^{2}}$,

where $w(n)$ is the input data series; $p$ is the order of AR process; $a_{k}(k=0,1, \ldots, p)$ and $\sigma_{w}^{2}$ are the parameters to be evaluated in the AR model.

With the frequency-domain features obtained by the PSDs of contact wire irregularity, researchers have attempted to use fitting functions to quantitatively describe these features. Reference [58] proposed to use the fractional polynomial function to fit the PSD of measured contact wire irregularity:

$S_{1}(k)=\frac{A+B k}{1+C k+D k^{2}}$,

where $A, B, C$ and $D$ are fitting parameters. Similarly, the exponential function is employed for the same purpose in [54] as follows:

$S_{2}(k)=\exp \left(\sum_{i=1}^{n} a_{i}(\ln k)^{i}-a_{0}\right)$

where $a_{i}(i=1,2, \ldots, n)$ are fitting parameters that differ for different types of catenary structure. The fitting functions provide a new way to establish the baseline for catenary state evaluation. Moreover, based on the fitting results using measurement data from different railway lines, synthetic contact wire irregularity data can be generated by inverse Fourier transform [34] or trigonometric series method [58] and applied to simulations. Figure 13a depicts an example of the PSD of contact wire irregularity and its fitting curve. Figure 13b shows the comparison 


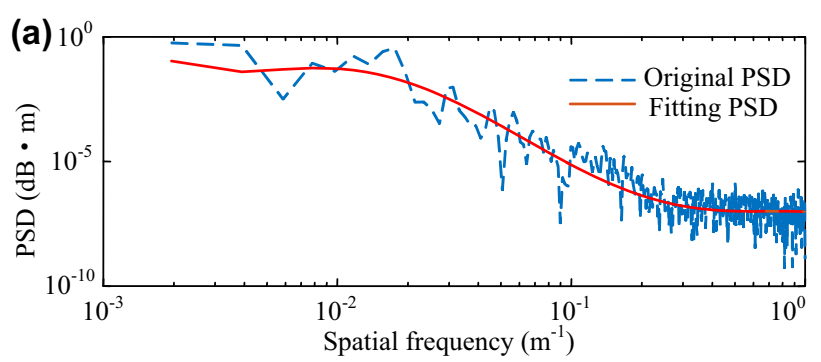

(b)

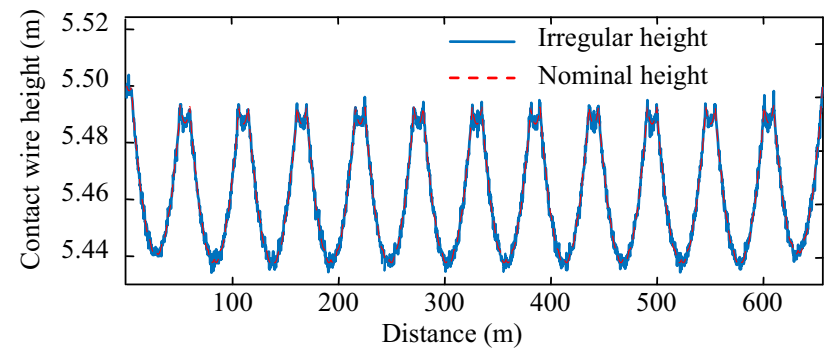

Fig. 13 Contact wire irregularity spectrum (a) and the simulation of contact wire irregularity (b)

between the contact wire nominal height with and without synthetic contact wire irregularity generated from the fitting curve.

\subsection{Dynamic state evaluation of catenary system}

Because of the excitation caused by pantograph passages, the contact wire is uplifted and vibrating as the pantograph slides through. Therefore, the geometric condition of contact wire, namely the contact wire irregularity can only represent the pre-operation condition of catenary system. The catenary performance during operation still needs to consider the pantograph-catenary dynamic coupling. Under high-speed operations, the mutual effect between pantograph and catenary becomes more intense than under conventional speeds. Thus, the dynamic state evaluation based on dynamic measurement data is more directly related to the dynamic performance of catenary system. It can provide in-depth insight and guidance for optimizing the design and operation of both pantograph and catenary.

\subsubsection{Dynamic state evaluation based on PSD}

In the dynamic state evaluation of catenary system, the involved dynamic measurement data are actually the reflection of pantograph-catenary dynamic characteristics. So, it is not only for the state evaluation of catenary system, but also for seeking potential improvements of current collection quality and service life. For conventional speed lines, indicators employed for estimating the current collection quality mainly include the mean, standard deviation, maximum, minimum of measurement data, and also the contact loss rate and arcing rate, etc. They are all considered as basic time-domain statistics. Although these indicators are simple and useful for judging the unfavorable current collection quality, they cannot sufficiently reflect the characteristic of the dynamic behavior. Therefore, researchers started to employ frequency analysis methods to investigate the relationship between contact wire irregularity and current collection quality. Methods such as time-domain statistics within limited frequency bandwidth [133] and PSD evaluation [124] were adopted to analyze the pantograph-catenary contact force. The pantograph-catenary contact force was regarded as the key parameter that directly reflects the current collection quality. So, the frequency-domain feature of the contact force was frequently analyzed by the PSD evaluation [134]. Based on the aforementioned AR spectrum, Ref. [132] employed contact force data to establish the catenary spectrum for the dynamic state evaluation and compared the spectrum features from different railway lines, operation speeds, pantograph-catenary couples and environmental wind speeds. Similar to the study of the PSDs of contact wire irregularity, Ref. [135] proposed to use the quadratic polynomial to fit the PSDs of contact force and extract the spectrum peaks to evaluate the catenary dynamic state. The fitting function is as follows:

$S_{3}(k)=c_{1} k^{2}+c_{2} k+c_{3}$,

where $c_{1}, c_{2}$ and $c_{3}$ are fitting parameters. Figure 14 depicts the PSDs of contact force under different operation speeds from the same line and the fitting results using (29). It indicates that the frequency feature of PSDs has certain correlation with the increase in speed.

Meanwhile, Kusumi et al. [136] analyzed the waveform of the PSD of contact force and proposed that the PSD of contact force can be used for catenary state diagnosis. Rønnquist et al. [137] employed the AR spectrum of the contact wire dynamic displacement to observe the frequency variation of contact wire vibration. Kudo et al. [138] adopted the bispectrum to analyze the low-frequency components of contact force. Kim [139] used spectral analysis to identify the frequency components in contact force and discussed their correlation catenary structure and pantograph inherent frequency. Han et al. [140] proposed to employ the dynamic vertical displacements of contact wire and pantograph to compare their AR spectrums and evaluate the dynamic interaction. In [141, 142], based on the ensemble empirical mode decomposition, the error measurement data in contact force are eliminated and the frequency components in contact force are extracted to evaluate the catenary dynamic state. 

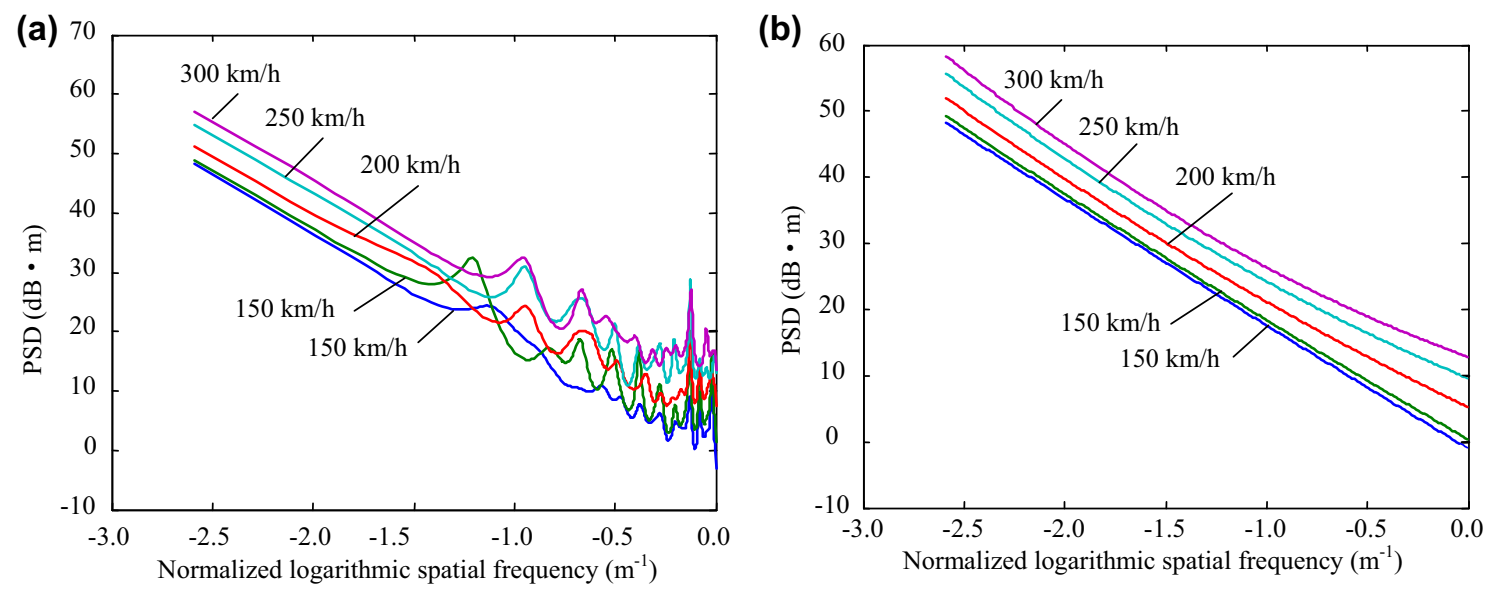

Fig. 14 Contact force spectrum (a) and fitting results under the train speed from 100 to $300 \mathrm{~km} / \mathrm{h} \mathrm{(b)}$

In summary, frequency analysis is an important way to evaluate the dynamic state of catenary system, or the pantograph-catenary interaction in a broad sense. The PSD analysis is the most frequently adopted method for frequency analysis. However, the dynamic state evaluation of catenary system based on PSD can reveal the spectral energy distribution along the frequency, which considers the data series as a whole and leaves the local features related to time or distance behind. For example, Fig. 15a depicts the simulation result of contact force under $300 \mathrm{~km} / \mathrm{h}$ operation speed, and Fig. $15 \mathrm{~b}$ depicts the corresponding AR spectrum. It can be seen that only the frequencies correlated with the catenary structure, namely the span distance and inter-dropper distance can be identified in the spectrum. For the in-depth dynamic state evaluation, these features may not be enough, particularly for the state evaluation of local structures.

\subsubsection{Dynamic state evaluation based on time-frequency analysis}

The time-frequency analysis is developed in particular to obtain the local frequency distribution that the one-dimensional Fourier transform or the PSD could not reveal. With the signal energy distribution on the time-frequency plane, the frequency variation with time or distance can be identified as local features. Currently, there is a small amount of literature that has employed the time-frequency analysis for catenary measurement data analysis and state evaluation. Rønnquist et al. [137] adopted the short-time Fourier transform to observe the frequency variation of contact wire vibration during pantograph passage. Kudo et al. [36] discussed the feasibility of using the wavelet transform of contact force for catenary defect diagnosis. Usuda et al. [143] also applied the short-time Fourier transform to the contact force and predicted the contact wear rate. Mariscotti et al. [144] performed the time-frequency analysis on the current signal from catenary and evaluate the current collection quality. Zhang [145] employed the wavelet transform to study the time-frequency characteristics of contact force in different frequency bands and diagnosed the contact wire irregularity.

Among all the time-frequency analysis methods, the Zhao-Atlas-Mark distribution (ZAMD) was tested to be suitable for the time-frequency representation of contact force [146]. For a contact force signal $x(t)$, its time-frequency representation based on ZAMD is defined as

$$
\begin{array}{r}
C(t, \omega ; \phi)=\frac{1}{4 \pi^{2}} \iiint \phi(t, v) \mathrm{e}^{-\mathrm{j} \omega \tau} \mathrm{e}^{-\mathrm{j} v(t-u)} \\
\times x\left(u+\frac{\tau}{2}\right) x^{*}\left(u-\frac{\tau}{2}\right) \mathrm{d} u \mathrm{~d} \tau \mathrm{d} v,
\end{array}
$$

where $t$ and $\omega$ are, respectively, the time and frequency of the signal; the asterisk $(*)$ indicates complex conjugate; $u$, $\tau$ and $v$ are, respectively, the time instant, time shift and frequency shift of the integral computation; $\phi(t, v)$ is the kernel function defined by

$\phi(t, v)=g(\tau) \frac{\sin (|\tau| v / \beta)}{v / 2}$,

where $g(\tau)$ is the time window; $\beta$ is the slope parameter of the kernel and normally $\beta \geq 2$. Figure 16 depicts the resulting time-frequency representation of the contact force depicted in Fig. 15a. It can be seen that in the contact force signal, most energy is concentrated in the low-frequency range, representing the wavelengths induced by the span distance and inter-dropper distance. Also, there are two frequency components in the high-frequency range that are beyond the scope of catenary structural wavelength [147]. They are considered to be caused by pantograph head vibration. Figure 17 shows the time-frequency representation of the contact force under simulated contact 

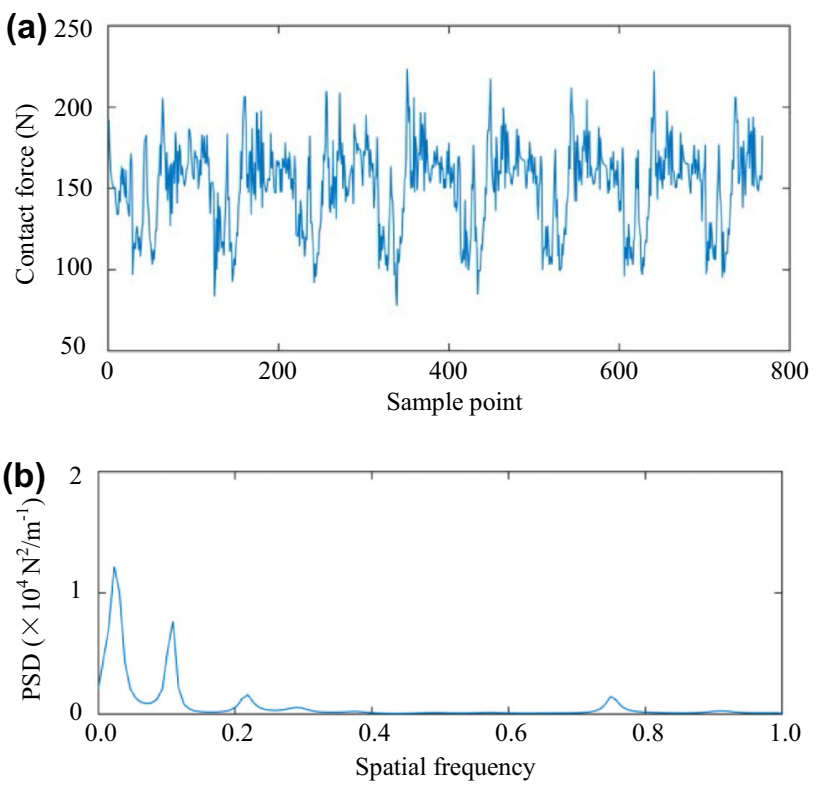

Fig. 15 Contact force simulation signal (a) and its PSD valuation (b)

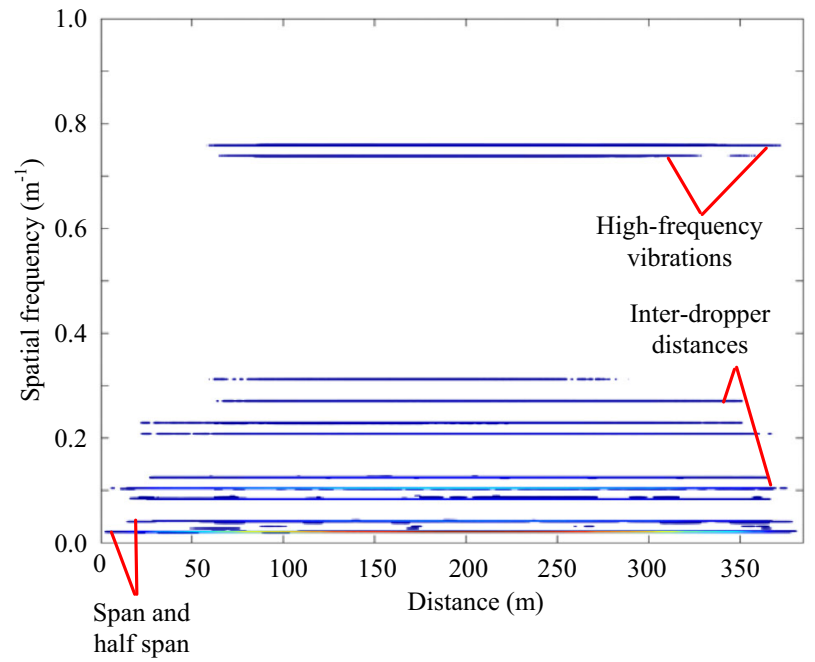

Fig. 16 Time-frequency analysis of the pantograph-catenary contact force based on ZAMD

wire irregularity. The contact wire irregularity is composed of a 3-m wavelength global cosine waveform, a 1-m wavelength local cosine waveform and a $2-m$ wavelength local cosine waveform. The distance intervals of two local irregularities are $[101,110.5 \mathrm{~m}]$ and $[240,288 \mathrm{~m}]$, respectively.

It can be seen from Fig. 17 that the time-frequency representation can not only reflect the frequency or wavelength of contact wire irregularities, but also the location of the local irregularities.

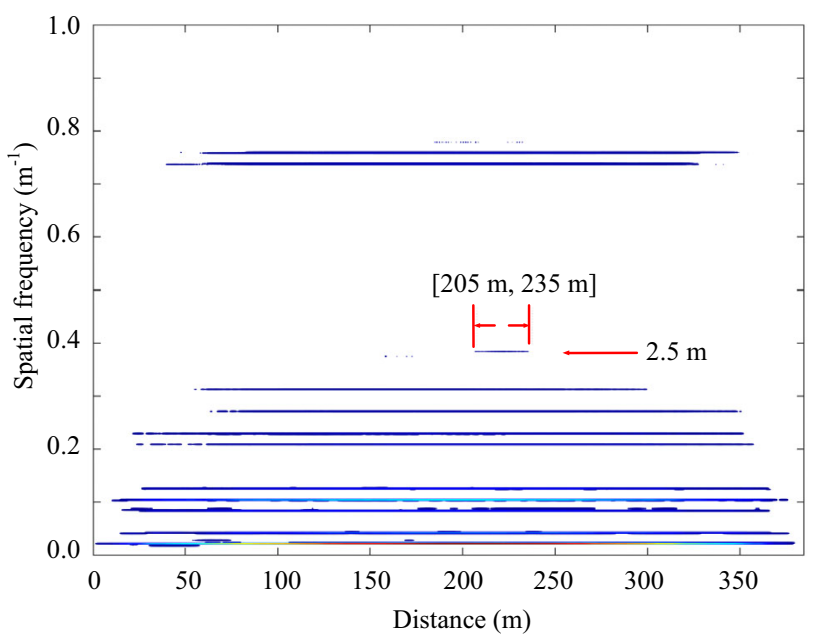

Fig. 17 Time-frequency analysis of the pantograph-catenary contact force under contact wire irregularity based on ZAMD

In, the application of time-frequency analysis to the dynamic state evaluation of catenary system is still in its trial phase. This method is a promising technique for dynamic state evaluation since interpretation of time-frequency characteristics satisfies the emerging needs for the feature analysis of catenary dynamic data and defect diagnosis; however, the physical meanings of different frequency feature require further investigations.

\section{Research prospects}

\subsection{Modeling and simulation}

1. Current static and dynamic modeling of catenary system mainly focuses on the simulation of the single anchor section, but seldom considers the multi-anchor section and different span lengths in actual situations. The research on the modeling and dynamic characteristics for the curve section and rigid flexible connection zone of catenary is also an important research direction in the future.

2. At present, the finite element model is the most widely used model. How to improve the solving efficiency on the premise of ensuring the nonlinear precision is an important development direction of the catenary dynamic simulation. Since the catenary span is long and the dynamic response precision is high, relatively dense meshing is usually adopted, which leads to low computation speed and high simulation cost. Carnicero et al. [40] proposed a dynamic grid implementation scheme for moving loads, whose application to the dynamic simulation of pantograph-catenary system 
can greatly improve the efficiency. Therefore, the efficient numerical methods for the nonlinear catenary system should be improved according to different working conditions, such as environment wind field and double pantograph operation.

3. For the dynamic simulation of catenary in wind environment, the existing research mainly focuses on the unidirectional fluid-solid coupling; nevertheless, the simulation method cannot reach a satisfactory precision when the vibration amplitude is large. Therefore, it is necessary to consider the application of bidirectional strong fluid-solid coupling technique to the simulation of wind-induced vibration of catenary.

4. The accuracy verification of catenary dynamic model has been a difficult problem in this field, and the corresponding standards for the correctness of the simulation model have not been established in China. Bruni et al. [132] compared the results of static and dynamic simulation models of pantograph-catenary system and proposed a new evaluation criterion. But, the proposed verification methods still stay in the current mainstream pantograph-catenary simulation models, and the results have not been compared with the actual measured data.

5. Due to the complex working environment of catenary system, besides the wind load and the impact of the pantograph, it will also be affected by other environmental factors, such as electromagnetic force, catenary friction, surface irregularities. In [148], it is found that the influence of the electromagnetic force generated by the fault current on the contact force of pantographcatenary system cannot be ignored. The influence of friction induced vibration and surface irregularities on the dynamic behavior of pantograph-catenary system is also great [149]. In previous studies, the modeling of these environmental factors is relatively simplified, and the mechanical behavior of catenary is difficult to fully reflect in the actual condition. As a result, simulations can generally obtain a better current collection quality compared with that in actual situations. Therefore, the modeling and simulation of catenary in actual working conditions will be one of the main directions in the future research.

\subsection{Detection and evaluation}

1. For the non-contact image detection technology of catenary, the main way to capture images is through the cameras mounted in the catenary inspection car roof. In the process of operation, the vibration of car body will inevitably occur in various forms. Some researchers have done a lot of studies on this problem. However, how to realize the full compensation for the vibration of car body is still a problem to be solved, which is limited by the complexity of the body vibration and the precision of sensors for detection.

2. Based on the image processing technology, the fault detection algorithm for key components of catenary suspension device is unable to meet the requirements of all-weather real-time online detection, due to the constraints of weather and illumination. Therefore, how to improve the existing detection algorithms and improve the performance of image acquisition equipment is the main problem in the future.

3. The current catenary fault detection algorithms are relatively simple and mainly based on machine learning and pattern recognition, which cannot fully utilize the existing image data. Deep learning detection technology may become the future research trend of high-speed railway catenary detection technology.

4. Some problems still exist in current evaluation methods including the oversimplification of evaluation methods and indicators. It is difficult to exploit the hidden bad state information in data, which is unfavorable to the operation and maintenance of the highspeed catenary. Therefore, research on the evaluation of catenary is changing from the time-domain method to the frequency-domain method. For the spectral evaluation method, the complex operation condition and the bad state of catenary should be considered comprehensively. In addition, time-frequency evaluation methods need a large number of experiments and field data to verify the physical meaning of each wavelength component for improving the corresponding diagnostic methods.

5. Although a variety of evaluation methods and evaluation indexes have been proposed, there is still a lack of an integrated diagnosis and evaluation system of catenary that can guide the operation and maintenance of actual high-speed catenaries. To this end, how to integrate various existing evaluation methods to construct a spectrum-based unified evaluation system according to the actual high-speed railway line conditions will be an important topic worthy of further study.

6. Whether using static or dynamic evaluation, the research and development of high-speed railway catenary evaluation are based on the establishment and improvement of the current high-speed railway ' $6 \mathrm{C}$ ' system in China. For the large data platform of catenary provided by the ' $6 \mathrm{C}$ ' system, conventional evaluation methods will not be unable to make full use of the available information and data; consequently 
data mining and data fusion technology will become an important research topic in the future.

\subsection{Prospects on study of technical standard}

The technical standards on high-speed pantograph-catenary current collection quality and service performance are necessary to be improved. Standards for current practice adopt the statistical minimal value to evaluate the contact loss, which, however, is very simple and cannot consider the complex circumstances. Hence in the future, various dimensions of data should be analyzed according to the characteristics of catenary. A improved standard should be proposed to evaluate the current collection quality and service performance, which should include the following three aspects:

1. Wave propagation along catenary: The highest wave propagation speed is a critical index to determine the highest driving speed of a train. Because the maximum wave propagation speed is very close to the driving speed of trains, improving the utilization rate of wave speed for existing railways is imperative. Therefore, the wave propagation should be studied considering the effect of different components and different working conditions. The reflection and transmission coefficients in the dropper/registration points should be standardized for the optimization of the existing railway catenary.

2. The prediction of the fatigue and wear of contact wire: The previous studies mainly predict the fatigue of contact wire to evaluate the service performance of catenary, but the prediction accuracy of fatigue has not been verified. Therefore, the spectrum of catenary load should be studied in detail; the predictions of fatigue and wear should be standardized according to the real characteristics of catenary.

3. Standard of evaluating current collection quality: Referring to EN 50318, higher speed level and more complex circumstances should be considered for new evaluation standard of the current collection quality. Time-frequency analysis method should be adopted to reveal the factors influencing the separation between the pantograph and the catenary. The new standard should be proposed from multiple perspectives.

Acknowledgements This study was supported by the National Natural Science Foundation of China (U1434203, 51377136, 51405401, 51407147), Sichuan Province Youth Science and Technology Innovation Team Project (2016TD 0012), China Railway Corporation Science and Technology Research and Development Plan of major Projects (2013J010-B, 2015J008-A).
Open Access This article is distributed under the terms of the Creative Commons Attribution 4.0 International License (http:// creativecommons.org/licenses/by/4.0/), which permits unrestricted use, distribution, and reproduction in any medium, provided you give appropriate credit to the original author(s) and the source, provide a link to the Creative Commons license, and indicate if changes were made.

\section{References}

1. Wu G, Wei W, Gao G et al (2016) Evolution of the electrical contact of dynamic pantograph-catenary system. J Mod Transport 24(2):132-138

2. Standardization E C F E. EN50318 (2002) Current collection systems-validation of simulation of the dynamic interaction between pantograph and overhead contact line. European Standards, Brussels

3. Chater E, Ghani D, Giri F et al (2015) Output feedback control of pantograph-catenary system with adaptive estimation of catenary parameters. J Mod Transport 23(4):252-261

4. Li F, Su Q (1996) The dynamic model and differential equations of the catenary. J Chang Railw Univ 14(2):90-93 (in Chinese)

5. KieBling F, Puschmann R, Schmieder A (2000) Contact lines for electrical railways: planning-design-implementation. China Electric Power Press, Beijing

6. Wu T, Brennan M (1999) Dynamic stiffness of a railway overhead wire system and its effect on pantograph-catenary system dynamics. J Sound Vib 219(3):483-502

7. Fang Y, Gao S (2010) Integral dropper assembly for overhead contact line of high-speed railway. J Southwest Jiaotong Univ 45(5):763-766 (in Chinese)

8. Ruan J, Yan F, Li H (2012) Static modeling of overhead contact system of high-speed electrified railway. J China Railw Soc 34(8):20-25 (in Chinese)

9. Song Y, Liu Z, Wang H et al (2015) Establishment of 3D model for catenary and nonlinear solution for its wind deflection. J China Railw Soc 37(4):30-38 (in Chinese)

10. Zhou N, Li R, Zhang W (2009) Modeling and simulation of catenary based on negative sag method. J Traffic Transp Eng 9(4):28-32 (in Chinese)

11. Lopez-Garcia O, Carnicero A, Torres V (2006) Computation of the initial equilibrium of railway overheads based on the catenary equation. Eng Struct 28(10):1387-1394

12. Lee J, Park T (2012) Development of a three-dimensional catenary model using cable elements based on absolute nodal coordinate formulation. J Mech Sci Technol 26(12):3933-3941

13. Jung S, Kim Y, Paik J et al (2012) Estimation of dynamic contact force between a pantograph and catenary using the finite element method. J Comput Nonlinear Dyn 7(4):041006

14. Tur M, García E, Baeza L et al (2014) A 3D absolute nodal coordinate finite element model to compute the initial configuration of a railway catenary. Eng Struct 71:234-243

15. Song Y, Liu Z, Wang $\mathrm{H}$ et al (2015) Nonlinear modelling of high-speed catenary based on analytical expressions of cable and truss elements. Veh Syst Dyn 53(10):1455-1479

16. Hou Y, Liu Z, Song Y et al (2014) Modeling of steady state of electric railway catenary based on nonlinear cable and truss. J China Railw Soc 36(7):24-29 (in Chinese)

17. Potsch U, Verbesserung N (2000) Verfahen zur Simulationvon Stromabnehmern Kettenwerk Systemen. VDI Verlag, Dusseldorf 
18. Finner L, Poetsch G, Sarnes B et al (2015) Program for catenary-pantograph analysis, PrOSA statement of methods and validation according EN 50318. Veh Syst Dyn 53(3):305-313

19. Ambrósio J, Rauter F, Pombo J et al (2010) Dynamics of highspeed train pantograph-catenary co-simulation of finite element and multibody codes. In: Proceedings of the international symposium on computational mechanics and the 12th international conference on the enhancement and promotion of computational methods in engineering and science, vol 1233, no 1. AIP Publishing, Melville, pp 213-218

20. Antunes P, Mósca A, Ambrósio J et al (2012) Development of a computational tool for the dynamic analysis of the pantographcatenary interaction for high-speed trains. In: Proceedings of the 11th international conference on computational structures technology. Civil-Comp Press, Stirlingshire

21. Ambrósio J, Pombo J, Rauter F et al (2009) A memory based communication in the co-simulation of multibody and finite element codes for pantograph-catenary interaction simulation. In: Bottasso CL (ed) Multibody dynamics, vol 12. Springer, Dordrecht, pp 231-252

22. Rauter F, Pombo J, Ambrósio J et al (2007) Contact model for the pantograph-catenary interaction. J Syst Des Dyn 1(3):447-457

23. Ambrósio J, Pombo J, Pereira M et al (2012) Recent developments in pantograph-catenary interaction modelling and analysis. Int J Railw Technol 1(1):249-278

24. Ambrósio J, Pombo J, Pereira M et al (2012) A computational procedure for the dynamic analysis of the catenary-pantograph interaction in high-speed trains. J Theor Appl Mech 50(3):681-699

25. Rauter F, Pombo J, Ambrósio J et al (2007) Multibody modeling of pantographs for pantograph-catenary interaction. In: IUTAM symposium on multiscale problems in multibody system contacts, vol 1. Springer, Dordrecht, pp 205-226

26. Ambrósio J, Rauter F, Pombo J et al (2011) A flexible multibody pantograph model for the analysis of the catenary-pantograph contact. In: Arczewski K, Blajer W, Fraczek J, Wojtyra M (eds) Multibody dynamics, vol 23. Springer, Dordrecht, pp 1-27

27. Ambrósio J, Pombo J, Pereira M (2013) Optimization of highspeed railway pantographs for improving pantograph-catenary contact. Theor Appl Mech Lett 3(1):013006

28. Cho Y, Lee K, Park Y et al (2010) Influence of contact wire presag on the dynamics of pantograph-railway catenary. Int J Mech Sci 52(11):1471-1490

29. Cho Y (2008) Numerical simulation of the dynamic responses of railway overhead contact lines to a moving pantograph, considering a nonlinear dropper. J Sound Vib 315(3):433-454

30. Andersson E, Fröidh O, Stichel S et al (2014) Green train: concept and technology overview. Int J Rail Transp 2(1):2-16

31. Liu Z, Jönsson PA, Stichel S et al (2014) Implications of the operation of multiple pantographs on the soft catenary systems in Sweden. Proc Inst Mech Eng F J Rail 230(3):0954409714559317

32. Facchinetti A, Bruni S (2012) Hardware-in-the-loop hybrid simulation of pantograph-catenary interaction. J Sound Vib 331(12):2783-2797

33. Bruni S, Bucca G, Collina A et al (2012) Numerical and hardwarein-the-loop tools for the design of very high speed pantographcatenary systems. J Comput Nonlinear Dyn 7(4):041013

34. Van Vo O, Massat JP, Laurent C et al (2014) Introduction of variability into pantograph-catenary dynamic simulations. Veh Syst Dyn 52(10):1254-1269

35. Massat J, Laine J, Bobillot A (2006) Pantograph-catenary dynamics simulation. Veh Syst Dyn 44(sup1):551-559

36. Massat J, Laurent C, Bianchi J et al (2014) Pantograph catenary dynamic optimisation based on advanced multibody and finite element co-simulation tools. Veh Syst Dyn 52(sup1):338-354

37. Carnicero A, Lopez-Garcia O, Torres V et al (2006) An algorithm based on finite element method and catenary equation to compute the initial equilibrium of railway overhead. Paper presented at 8th international conference on computational structures technology, Las Palmas de Gran Canaria (Espana), 12-15 Sept 2006

38. Lopez-Garcia O, Carnicero A, Maroño J (2007) Influence of stiffness and contact modelling on catenary-pantograph system dynamics. J Sound Vib 299(4):806-821

39. Carnicero A, Jimenez-Octavio J, Sanchez-Rebollo C et al (2012) Influence of track irregularities in the catenary-pantograph dynamic interaction. J Comput Nonlinear Dyn 7(4):041015

40. Jimenez-Octavio J, Carnicero A, Sanchez-Rebollo C et al (2015) A moving mesh method to deal with cable structures subjected to moving loads and its application to the catenary-pantograph dynamic interaction. J Sound Vib 349:216-229

41. Yamashita Y, Ikeda M (2012) Advanced active control of contact force between pantograph and catenary for high-speed trains. Q Rep RTRI 53(1):28-33

42. Ikeda M, Nagasaka S, Takayuki A (2001) A precise contact force measuring method for overhead catenary system. In: WCRR 2001

43. Usuda T, Ikeda M, Yamashita Y (2011) Method for detecting step-shaped wear on contact strips by measuring catenary vibration. Q Rep RTRI 52(4):237-243

44. Alberto A, Benet J, Arias E et al (2008) A high performance tool for the simulation of the dynamic pantograph-catenary interaction. Math Comput Simul 79(3):652-667

45. Benet J, Cuartero N, Cuartero F et al (2013) An advanced 3Dmodel for the study and simulation of the pantograph catenary system. Transp Res C Emerg Technol 36:138-156

46. Seo J, Kim S, Jung I et al (2006) Dynamic analysis of a pantograph-catenary system using absolute nodal coordinates. Veh Syst Dyn 44(8):615-630

47. Lee J, Park T, Oh H et al (2015) Analysis of dynamic interaction between catenary and pantograph with experimental verification and performance evaluation in new high-speed line. Veh Syst Dyn 53(8):1117-1134

48. Shabana A, Zaazaa K, Sugiyama H (2007) Railroad vehicle dynamics: a computational approach. CRC Press, Boca Raton

49. García-Vallejo D, Mayo J, Escalona J et al (2004) Efficient evaluation of the elastic forces and the Jacobian in the absolute nodal coordinate formulation. Nonlinear Dyn 35(4):313-329

50. Mei G (2010) The dynamic study of pantograph/catenary system. Thesis, Southwest Jiaotong University Graduate

51. Zhang W, Liu Y, Mei G (2006) Evaluation of the coupled dynamical response of a pantograph-catenary system: contact force and stresses. Veh Syst Dyn 44(8):645-658

52. Liu Y, Zhang W, Mei G (2003) Study of dynamic stress of the catenary in the pantograph/catenary vertical coupling movement. J China Railw Soc 25(4):23-26 (in Chinese)

53. Zhang W, Mei G, Wu X et al (2005) A study on dynamic behaviour of pantographs by using hybrid simulation method. Proc Inst Mech Eng F J Rail 219(3):189-199

54. Zhang W, Mei G, Wu X et al (2002) Hybrid simulation of dynamics for the pantograph-catenary system. Veh Syst Dyn 38(6):393-414

55. Mei G, Zhang W (2003) Study on dynamics of rigid suspension catenary. J China Railw Soc 25(2):24-29 (in Chinese)

56. Mei G, Zhang W, Zhao $\mathrm{H}$ et al (2006) A hybrid method to simulate the interaction of pantograph and catenary on overlap span. Veh Syst Dyn 44(sup1):571-580

57. Zhang W, Mei G, Chen L (2000) Analysis of the influence of catenary's sag and irregularity upon the quality of currentfeeding. J China Railw Soc 22(6):50-54 (in Chinese)

58. Jiang Y, Zhang W, Song D (2015) Study on the contact wire unevenness of high-speed railway. J China Railw Soc 37(2):34-38 (in Chinese) 
59. Zhigang Liu, Song Y, Liu Y (2015) Aeolian vibration characteristics of electrified high-speed railway catenary. J Southwest Jiaotong Univ 50(1):1-6 (in Chinese)

60. Liu Z, Han Z, Hou Y et al (2013) Modified formula of wave motion velocity of catenary inclusive of air damping. J China Railw Soc 35(1):41-45 (in Chinese)

61. Liu Y, Liu Z, Song Y et al (2014) Simulation calculation and wind tunnel test of static aerodynamic parameters of high-speed railway contact line. J China Railw Soc 36(5):33-38 (in Chinese)

62. Wang H, Liu Z, Song Y et al (2015) Aerodynamic parameters simulation and wind-induced vibration responses of contact wire of high-speed railway. J Vib Shock 34(6):6-12 (in Chinese)

63. Xie Q, Wang W, Li H (2013) Wind tunnel test on the aerodynamic characteristics of contact wire for high-speed railway. China Railw Sci 6:75-82 (in Chinese)

64. Xie Q, Wang W, Zhang H et al (2014) Wind tunnel test on aerodynamic force characteristics of ice coating contact wire for high-speed railway. China Railw Sci 35(1):78-85 (in Chinese)

65. Zhang J, Liu Z, Lu X et al (2015) Study on aerodynamics development of high-speed pantograph and catenary. J China Railw Soc 37(1):7-14 (in Chinese)

66. Liu Z, Hou Y, Han Z et al (2013) Analysis on dynamic characteristics of high-speed railway catenary based on wind field simulation. J China Railw Soc 35(11):21-28 (in Chinese)

67. Pombo J, Ambrósio J, Pereira M et al (2009) Influence of the aerodynamic forces on the pantograph-catenary system for high-speed trains. Veh Syst Dyn 47(11):1327-1347

68. Pombo J, Ambrósio J (2013) Environmental and track perturbations on multiple pantograph interaction with catenaries in high-speed trains. Comput Struct 124:88-101

69. Zhao F, Liu Z, Han Z (2012) Simulation study on influence of stochastic wind field to dynamic behavior of pantograph-catenary system. J China Railw Soc 34(10):36-42 (in Chinese)

70. Li R, Zhou N, Zhang W et al (2013) Fluctuating wind field and wind-induced vibration response of catenary based on AR model. J Traffic Transp Eng 13(4):56 (in Chinese)

71. Cao S, Deng B, Ma S et al (2011) Fatigue reliability analysis of contact wire under wind load. Mech Sci Technol 30(10): 1664-1668 (in Chinese)

72. Song Y, Liu Z, Wang H et al (2014) Influence of high-speed railway catenary buffeting on pantograph-catenary current collection under fluctuating wind. J China Railw Soc 36(6):27-34 (in Chinese)

73. Song Y, Liu Z, Wang H et al (2016) Nonlinear analysis of windinduced vibration of high-speed railway catenary and its influence on pantograph-catenary interaction. Veh Syst Dyn 54(6):723-747

74. Song Y, Liu Z, Duan F et al (2017) Study on wind-induced vibration behavior of railway catenary in spatial stochastic wind field based on nonlinear finite element procedure. J Vib Acoust 140:011010

75. Han Z, Liu Z, Zhang G et al (2013) Overview of non-contact image detection technology for pantograph-catenary monitoring. J China Railw Soc 35(06):40-47 (in Chinese)

76. Chen T, Xiao J (2005) The study of a new type of overhead contact system deviation detecting method based on neural networks. Paper presented at 2005 China intelligent automation conference, Qingdao, China

77. Pan X, Zhang Y, Meng F et al (2011) Photo-electronic measurement system on geometry parameter of electric locomotive contact wire. Instrum Tech Sens 3:38-41 (in Chinese)

78. Liu Y, Han T, Liu H (2012) Study on OCS dynamic geometric parameters detection based on image processing. Railw Locomot Car 32(5):86-91 (in Chinese)

79. Zhang G, Ling C, Wang X et al (2014) Image detection system design for geometry parameters of contact line. J Tianjin Polytech Univ 33(5):57-62 (in Chinese)
80. He H (2013) High speed railway operation safety supervising and monitoring technology. China Railw 03:1-7 (in Chinese)

81. Zhang D, Yu L, Jian Xiao et al (2014) Study on high-speed and dynamic vision measurement approach for overhead catenary system geometric parameter inspection. Chin J Sci Instrum 35(08):1852-1859 (in Chinese)

82. Shi Y, Liu C, Guo Y et al (2014) Measurement system of geometric parameters for overhead line system based on binocular vision. Infrared Laser Eng 06:1936-1942 (in Chinese)

83. Zhang G, Liu Z, Liu W et al (2014) Non-contact detection of conductor height \& stagger of contact line based on camera calibration. J China Railw Soc 36(3):25-30 (in Chinese)

84. Liu W, Liu Z, Geng X et al (2015) Research on detection method for geometrical parameters of catenary system based on mean shift and particle filter algorithm. J China Railw Soc 37(11):30-36 (in Chinese)

85. Liu W, Liu Z, Zhang G et al (2014) Correction of detected values of catenary geometric parameters based on camera calibration and Kalman filtering. J China Railw Soc 36(09):28-33 (in Chinese)

86. Wang Y, You C, Liu B (2014) Catenary geometrical parameter detection method based on machine vision technology. J Lanzhou Jiaotong Univ 01:192-195 (in Chinese)

87. Zhang D, Yu L, Xiao J et al (2013) Computer vision approach to conductor rail detecting vehicle vibration compensation method and its application. J China Railw Soc 35(01):25-30 (in Chinese)

88. Fan H, Bian C, Zhu T et al (2010) Automatic detection of position line in contactless overhead contact system. J Comput Appl 12:102-103 (in Chinese)

89. Duan R, Zhao W, Huang S et al (2011) Method for high-speed corner detection based on the fuzzy ID3 decision tree. J Tsinghua Univ (Sci Technol) 51(12):1787-1791 (in Chinese)

90. Zhang T, Hao K, Duan R (2013) Dynamic detection algorithm of slope gradient of catenary locator based on computer vision technology. Railw Stand Des 01:105-108 (in Chinese)

91. Zhang Q, Yu L (2013) The application of computer vision in steady arm slope identification. Paper presented at high-speed railway catenary fitting safety and reliability technology, Baoji, China

92. Yu B, Chen T, Yu L et al (2014) Locator slope detection based on Hough transform in image processing. Urban Mass Transit 17(05):32-36 (in Chinese)

93. Wang X, Wu J, Xu K et al (2014) Identification of OCS locator based on AdaBoost algorithm. High Speed Railw Technol 5(3):9-12 (in Chinese)

94. Peng C, Gao X (2007) Foreign catenary wire wearing detection system. Chin Railw 4:66-68 (in Chinese)

95. Qing L, Gao X (2005) Application of linear CCD on the wear measurement of contact wire. Locomot Roll Stock Technol 4:011 (in Chinese)

96. Pan X, Zhang Y, Meng F et al (2011) Photo-electronic measurement system on geometry parameter of electric locomotive contact wire. Instrum Technol Sens 03:38-40 (in Chinese)

97. Wang F, Gu G (2014) Research on catenary abrasion image enhancement based on curvelet transform. Railw Stand Des 2:112-116 (in Chinese)

98. Zhou W (2012) Wind-deviation detection technique and numerical simulation research of railway catenary in wind area. Central South University, Changsha

99. Zhou W, Tian H (2013) An intensity-adaptive color image segmentation based on contrast stretching and its application in visual detection of catenary wind-deviation. J Cent South Univ (Sci Technol) 44(04):1708-1713 (in Chinese)

100. Zhang Z, Yu L, Chen T et al (2013) A study on the contamination overhead contact line system insulators based on grey relational analysis. Insul Surge Arresters 6:001 (in Chinese) 
101. Xie D, Sun Z (2014) The application of image recognition technology in catenary suspension status detection. Electr Railw 2:34-36 (in Chinese)

102. Zhang G, Liu Z, Han Y et al (2013) A fast fuzzy matching method of fault detection for rod insulators of high-speed railways. J China Railw Soc 35(05):27-33 (in Chinese)

103. Han Z, Liu Z, Yang H et al (2013) Insulator fault detection based on curvelet coefficients morphology and zonal energy method. J China Railw Soc 35(3):36-40

104. Yang H, Liu Z, Han Z et al (2013) Foreign body detection between insulator pieces in electrified railway based on affine moment invariant. J China Railw Soc 35(04):30-36 (in Chinese)

105. Zhang G, Liu Z (2014) Fault detection of catenary insulator damage/foreign material based on corner matching and spectral clustering. Chin J Sci Instrum 35(6):1370-1377 (in Chinese)

106. Yang H, Liu Z, Han Y et al (2013) Defective condition detection of insulators in electrified railway based on feature matching of speeded-up robust features. Power Syst Technol 37(8):2297-2302 (in Chinese)

107. Han Y, Liu Z, Han Z et al (2014) Fracture detection of ear pieces of catenary support devices of high-speed railway based on SIFT feature matching. J China Railw Soc 36(2):31-36 (in Chinese)

108. Zhong J, Liu Z, Zhang G et al (2017) Defective condition detection of swivel clevis pins in overhead contact system of high-speed railway. J China Railw Soc 39(6):65-71

109. Yang H, Liu Z (2016) Defective condition detection of rotary double ears of support device in electrified railway based on feature matching of SURF. J China Railw Soc 38(8):28-34

110. Han Y, Liu Z, Geng X et al (2017) Fracture detection of ear pieces in catenary support devices of high-speed railway based on HOG features and two-dimensional Gabor transform. J China Railw Soc 39(2):52-57

111. Chen J, Liu Z, Wang H et al (2017) Automatic defect detection of fasteners on the catenary support device using deep convolutional neural network. IEEE Trans Instrum Meas (in press)

112. Zhang G, Liu Z, Han Y et al (2017) High-speed railway catenary messenger wire bracket recognition and missing fault detection. J China Railw Soc 39(5):40-46 (in Chinese)

113. Ohta M (2005) Level crossings obstacle detection system using stereo cameras. Q Rep RTRI 46(2):110-117

114. Tong L, Zhu L, Yu Z et al (2012) Railway obstacle detection using onboard forward-viewing camera. J Transp Syst Eng Inf Technol 12(4):79-83 (in Chinese)

115. Dong H, Ge D, Qin Y et al (2010) Research on railway invasion detection technology based on intelligent video analysis. China Railw Sci 31(2):121-125

116. Li J, Chen Z, Wang M (2013) Moving target real-time detection of railway intrusion. J Railw Sci Eng 10(6):116-120

117. Aydin I, Karakose M, Akin E (2013) A robust anomaly detection in pantograph-catenary system based on mean-shift tracking and foreground detection. Proc IEEE Int Conf Syst Man Cybern 8215(2):4444-4449

118. Tang P, Jin W, Chen L (2014) Visual abnormality detection framework for train-mounted pantograph headline surveillance. In: 17th IEEE international conference on intelligent transportation systems, pp 847-852

119. Wang Q, Liang X, Liu Y et al (2014) Visual detection method for the invasion of slowly changing foreign matters to railway lines. China Railw Sci 35(3):137-143 (in Chinese)

120. Shi H, Chai H, Wang Y et al (2015) Study on railway embedded detection algorithm for railway intrusion based on object recognition and tracking. J China Railw Soc 37(7):58-65 (in Chinese)
121. Wu J (2010) Pantograph and Catenary System. Southwest Jiaotong University Press, Chengdu (in Chinese)

122. Carnevale M, Collina A (2016) Processing of collector acceleration data for condition-based monitoring of overhead lines. Proc Inst Mech Eng F J Rail 230(2):472-485

123. Boffi P, Cattaneo G, Amoriello L et al (2009) Optical fiber sensors to measure collector performance in the pantographcatenary interaction. IEEE Sens J 9(6):635-640

124. Aboshi M, Manabe K (2000) Analyses of contact force fluctuation between catenary and pantograph. Q Rep RTRI 41(4):182-187

125. Collina A, Fossati F, Papi M et al (2007) Impact of overhead line irregularity on current collection and diagnostics based on the measurement of pantograph dynamics. Proc Inst Mech Eng F J Rail 221(4):547-559

126. Bucca G, Collina A (2009) A procedure for the wear prediction of collector strip and contact wire in pantograph-catenary system. Wear 266(1):46-59

127. Bohol F, Yi H (1995) Study on the high-speed technology of the shinkansen current collection system. Electr Tract Lett 10:20-25

128. Aboshi M (2004) Precise measurement and estimation method for overhead contact line unevenness. IEEE Trans Ind Appl 124:871-877

129. Huan R, Jiao J, Su G et al (2012) Dynamics of pantographcatenary coupled system with contact wire vertical irregularities. J China Railw Soc 34(7):15-21 (in Chinese)

130. Xie J, Liu Z, Han Z et al (2009) Pantograph and overhead contact line coupling dynamic model simulation and analysis of imbalance of overhead contact line. Electr Railw 6:010 (in Chinese)

131. Liu Z, Han Z (2011) Review of researches on catenary spectrum in electrified railway. Electr Railw 1:1-3 (in Chinese)

132. Liu Z, Han Z (2013) Study on electrical railway catenary line spectrum based on AR model. J China Railw Soc 35(12):24-29 (in Chinese)

133. Bruni S, Ambrosio J, Carnicero A et al (2015) The results of the pantograph-catenary interaction benchmark. Veh Syst Dyn 53(3):412-435

134. Kim J, Chae H, Park B et al (2007) State sensitivity analysis of the pantograph system for a high-speed rail vehicle considering span length and static uplift force. J Sound Vib 303(3):405-427

135. Wang H, Liu Z, Han Z et al (2014) Feature extraction of pantograph-catenary contact force power spectrum of electrified railway. J China Railw Soc 36(11):23-28 (in Chinese)

136. Kusumi S, Fukutani T, Nezu K (2006) Diagnosis of overhead contact line based on contact force. Q Rep RTRI 47(1):39-45

137. Rønnquist A, Nåvik P (2015) Dynamic assessment of existing soft catenary systems using modal analysis to explore higher train velocities: a case study of a Norwegian contact line system. Veh Syst Dyn 53(6):756-774

138. Kudo S, Honda S, Ikeda M (2002) Contact force signal analysis of current collecting with bispectrum and wavelet. In: Proceedings of the 41st SICE annual conference, vol 4, pp 2478-2482

139. Kim J (2007) An experimental study of the dynamic characteristics of the catenary-pantograph interface in high speed trains. J Mech Sci Technol 21(12):2108-2116

140. Han Z (2013) The dynamic characteristics assessment of highspeed catenary-pantograph based on modern spectrum analysis and intelligent fault image identification. Southwest Jiaotong University, Chengdu

141. Han Z, Liu Z, Zhang X et al (2013) Pantograph-catenary contact force data analysis based on data correlation decomposed by EEMD. J China Railw Soc 35(9):25-30 (in Chinese)

142. Wang H, Liu Z, Song Y (2015) Analysis on wavelength components in pantograph-catenary contact force of electric railway 
based on multiple EEMD. J China Railw Soc 37(5):34-41 (in Chinese)

143. Usuda T (2007) Estimation of wear and strain of contact wire using contact force of pantograph. Q Rep RTRI 48(3):170-175

144. Mariscotti A, Marrese A, Pasquino N et al (2013) Time and frequency characterization of radiated disturbance in telecommunication bands due to pantograph arcing. Measurement 46(10):4342-4352

145. Zhang X (2013) The analysis of contact force between the pantograph and contact line in electrified railway via signal processing methods. Southwest Jiaotong University, Chengdu

146. Wang H, Liu Z, Song Y (2016) Time-frequency analysis of pantograph-catenary contact force and contact wire irregularity in high-speed railway based on ZAMD. J China Railw Soc 38(1):41-47 (in Chinese)

147. Liu Z, Wang H, Dollevoet R et al (2016) Ensemble EMD-based automatic extraction of the catenary structure wavelength from the pantograph-catenary contact force. IEEE Trans Instrum Meas 65(10):2272-2283

148. Zhao Y, Wu G, Gao G et al (2014) Study on electromagnetic force of pantograph-catenary system. J China Railw Soc 36(10):28-32 (in Chinese)

149. Qian W, Chen G, Zhang W et al (2013) Friction-induced, selfexcited vibration of a pantograph-catenary system. J Vib Acoust 135(5):521-523 